\title{
Parametric analysis on external dissipative link system for seismic protection of low rise R.C. buildings
}

\author{
Mario Lucio Puppio, Martina Ferrini \\ University of Pisa, Italy \\ mariolucio.puppio@ing.unipi.it,martina.ferrini90@gmail.com
}

\begin{abstract}
The seismic rehabilitation of existing R.C. and masonry buildings is a topical issue in Civil Engineering. A useful technique consists in the introduction of the external bracing system. This kind of intervention can be improved through the introduction of dissipative links, investigated here with the help of some examples. The links are made of common steel profiles: length, geometry and positioning are considered as design parameters. A general procedure of link-bracing optimization is proposed by applying a set of identical external restraints. The adopted dissipative links allow a cheaper and more effective design both in terms of ULS and of DLS: the damages are addressed in a small area allowing easy replacement of the links in case of an earthquake.
\end{abstract}

KEYWORDS. Seismic rehabilitation; Existing buildings; External bracing systems; Dissipative links; Structural optimization.

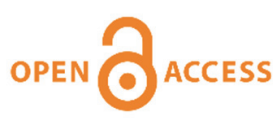

Citation: Puppio, M. L.., Ferrini, M., Parametric analysis on external dissipative link system for seismic protection of low rise R.C. buildings, Frattura ed Integrità Strutturale, 48 (2019) 706-739.

Received: 31.01.2019

Accepted: 06.02.2019

Published: 01.04.2019

Copyright: (C) 2019 This is an open access article under the terms of the CC-BY 4.0, which permits unrestricted use, distribution, and reproduction in any medium, provided the original author and source are credited.

\section{INTRODUCTION AND STATE OF THE ART}

\section{External retrofit with bracing systems}

$\checkmark$ he seismic enhancement of existing Reinforced Concrete (R.C.) structures, built before the introduction of seismic regulations, is a topical issue [1-3]. In recent years several researches have been carried out on this topic to study the behaviour of the external seismic consolidation systems.

In this sense, structural irregularity has a relevant role. In fact, structural response is significantly affected by geometric and material irregularity [4,5]. A relevant intervention should consider mechanical irregularity, particularly the high dispersion in concrete resistance [6]. The design of a new external bracing structure can satisfy this requirement [7].

Another critical issue is the respect of different aspects covered by technical norms, such as energy efficiency [8], fire protection [9] or the use of isolation systems. The optimization of the refurbishment of external walls or facades in terms of energy efficiency [a] or fire protection [b] or the design of seismic isolators [c] can modify the choices with the aim of minimizing the impact or the costs of intervention. 
Also, in the context of historical masonry buildings the improvement of seismic behaviour can be evaluated by different techniques, especially related to the fact that connections between vertical elements and between vertical and horizontal diaphragms are weak. For these issues, new approaches have recently been proposed, related to energy dissipation [10] and to rocking analysis of walls with horizontal restraints [11,12]. Indeed, steel tie-rods are generally the simplest and most effective tools to impede out-of-plane modes for both masonry and precast concrete structures [13,14] or to reduce relative displacements in case of flexible diaphragms [15].

There are various solutions to improve structural efficiency. One of the most interesting is the introduction of external bracing elements. In this case, the anti-seismic core can be realized with concrete and steel trusses. The trusses solution is characterised by the possible configurations (i.e. concentric $\mathrm{X}$, inverted $\mathrm{V}$, with links, etc.), the plan disposition and the adopted material. In this paper, different application to real cases are showed.

Furthermore, the creation of a new structure designed to absorb horizontal action is very relevant because (1) it is in line with the original static conception of the building; (2) it decreases the seismic action on the existing structure; (3) it presents less uncertainty compared to a traditional intervention on an existing structure. For these reasons the intervention with external bracing system finds a natural application in this case.

The design of a new anti-seismic braced structure is usually performed through dissipative diagonals. In this case it is natural to concentrate dissipation at the interface between the bracing system and the existing building by means of the installation of a dissipative interface.

Buildings similar in term of constructive typology, but different in term of architectural and structural demands, can be consolidated in different ways. This is the case with two R.C. low rise buildings, the "XXV April" primary school in Arcola (Italy) [16] and a social housing complex in Livorno (Italy) [17].

\section{Arcola}

The building of the "XXV April" primary school of Arcola (La Spezia, Italy) is composed of two floors with a R.C. frame. The seismic vulnerability is relevant due to plan asymmetry, ribbon windows and squat reduced section columns between the basement and the ground floor. The insertion of four external steel bracings (Fig. 1) significantly reduces the transverse loads on the R.C. frames.

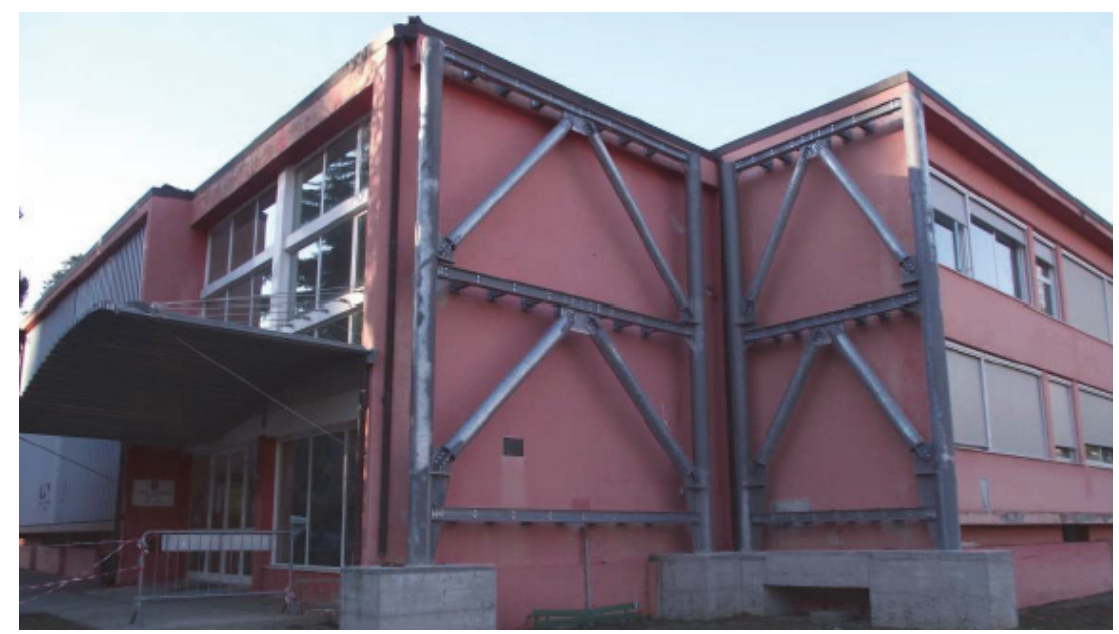

Figure 1: Steel frameworks used for the "XXV April" school in Arcola (Italy) [16].

The connection between the external retrofitting system and R.C. structure is ensured by horizontal short steel profiles. This makes it possible, in case of high-intensity earthquakes, to dissipate energy by bending.

\section{Livorno}

The case study in Livorno (Italy), is a three-storey pilotis R.C. social housing complex. Two different solutions are presented (Fig. 2). Solution A consists of the insertion of steel - glass frames only at the shorter length sides of the building. Solution $\mathrm{B}$ introduces multi-bracing frames on both directions. Both solutions are characterized by a traditional steel multi-braced frame in the centre of the building, but solution A has lower cost and impact. Because of the glass plates, the stiffness of the multi-bracing hybrid system can be used by inserting dissipative links in connection with the building. 

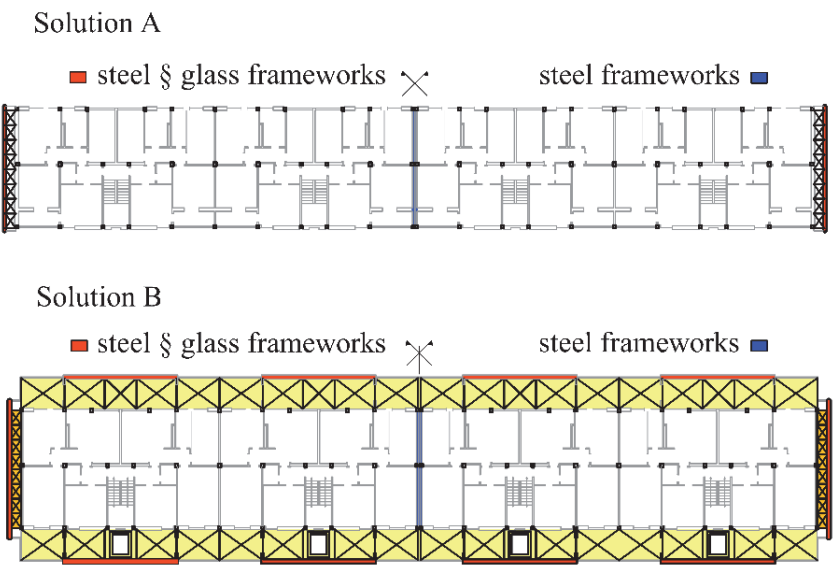

$\square$ longitudinal trusses

transversal trusses $\square$

Figure 2: Plan configurations of solution A and solution B for social housing in Livorno (Italy) [17].

In both cases, the intervention is almost external minimizing the interference with the internal parts of the construction.

\section{Comparative studies}

In 2015 a comparative study was carried out to analyse the behaviour of different brace configurations according to the Venezuelan code [18].

The structures were initially designed as moment resisting frames and integrated with six different bracing configurations: concentric and eccentric braces with or without horizontal and vertical links. (Fig. 3)

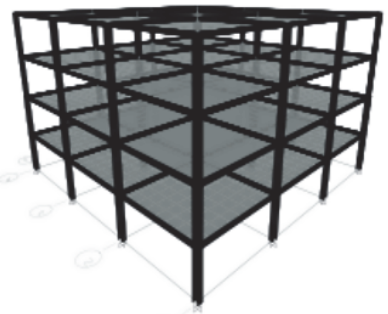

4-Storey MRF in X Braces (Configuration 1)

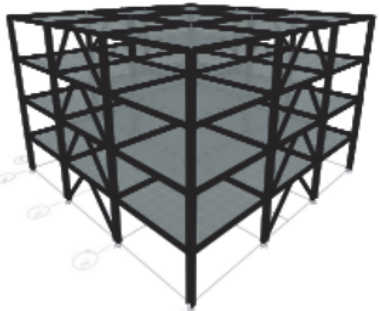
4-Storey EBF in inverted V Braces
with horizontal link (Configuration 4)

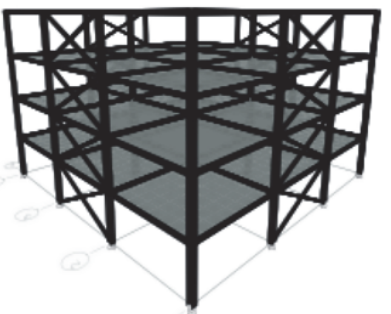

4-Storey CBF in $\mathrm{X}$ Braces (Configuration 2)

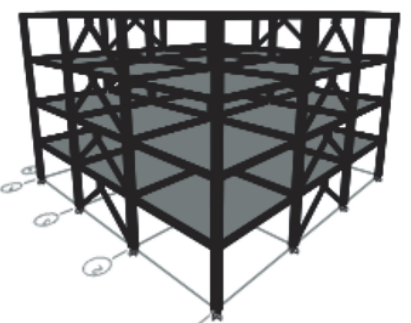

4-Storey EBF in inverted Y Braces (Configuration 5)

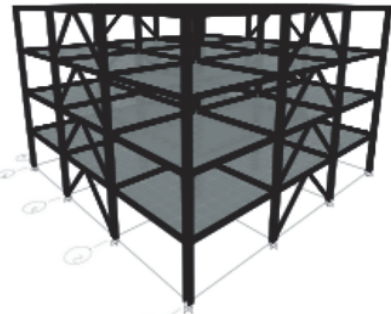

4-Storey $\mathrm{CBF}$ in inverted V Braces (Configuration 3)

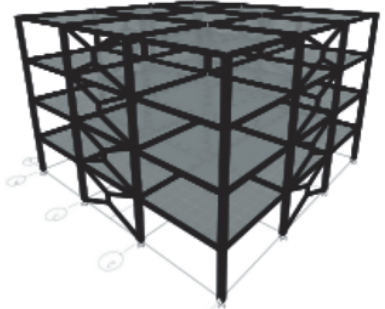

4-Storey EBF in X Braces with vertical link (Configuration 6)

Figure 3: 3D model of the six configurations studied (4-storey buildings) [18].

The models created were analysed carrying out non-linear static and incremental dynamic analysis. Short length links were performed to ensure a shear collapse.

\section{Calcinaia}

The "M. L. King" secondary school in Calcinaia (Pisa, Italy) is composed of three R.C. units built in 1969. (Fig. 4 and Fig. 5)[19]. 


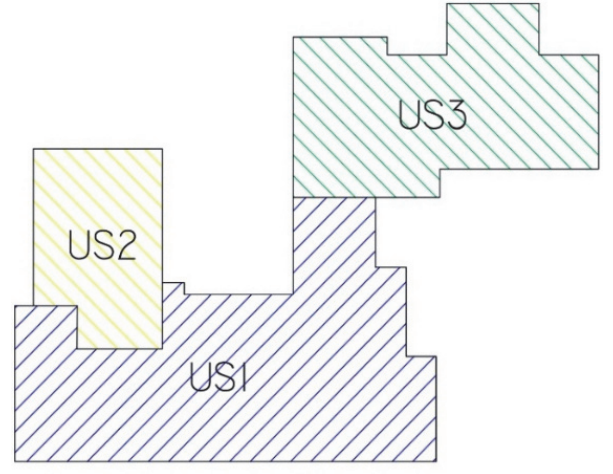

Figure 4: Schematic plan of the building with the indication of the structural units [19].

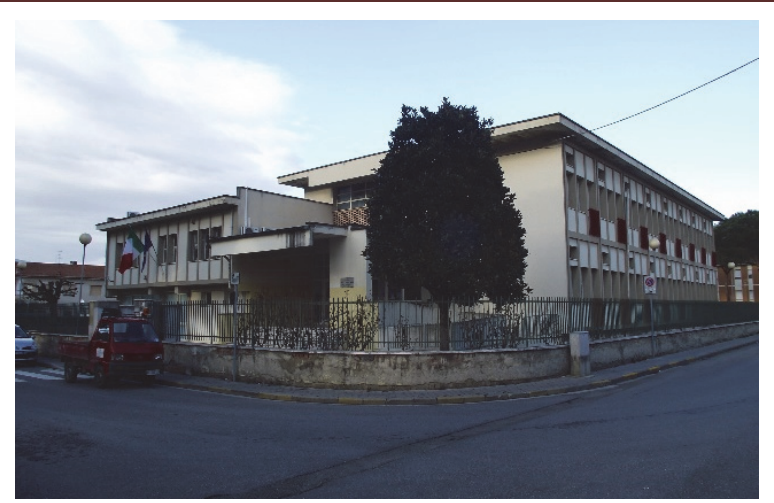

Figure 5: School main entrance [19].

The Structural Units SU1 and SU2 have two storeys (ground floor and first floor) with classrooms and laboratories; on the mezzanine floor there are the administration offices. In the SU3 there is a gym and a storage area for sports equipment. Only the structural unit containing the gym was examined; this was the subject of a seismic retrofitting in November 2016. Built in the late 1960s, the structure is characterized by poor quality of materials; moreover, the shape of the plan of the unit is much longer in one direction and this leads to important torsional deformations.

It is possible to highlight some critical points that determine the seismic vulnerability of the building:

- Asymmetry in plan with an irregular arrangement of the infills which are formed by two layers: full blocks outside and perforated blocks inside;

- Columns with reduced section compared to the beams;

- Presence of ribbon windows;

- Beam-column knots with brittle behaviour.

A chevron bracing system has been included as a consolidation intervention (Fig. 6 and Fig. 7).

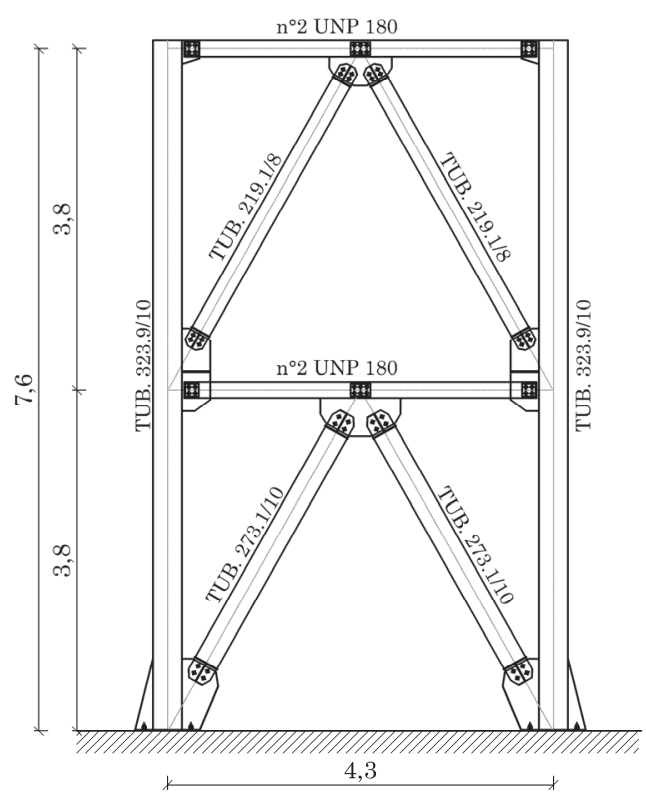

Figure 6: First typology of inverted V-bracing [20].

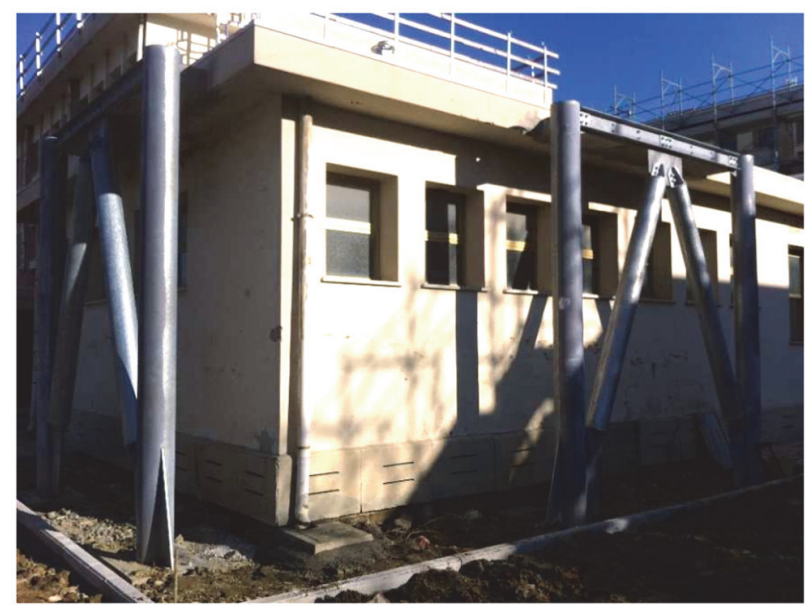

Figure 7: Northwest side view [20].

For the diagonals and columns, circular hollow steel profiles are used. This solution has undoubted advantages:

- Preservation of the existing resistant structure;

- $\quad$ Reduced work inside the structure;

- Uninterrupted school use;

- $\quad$ Restricted construction times; 


\section{- $\quad$ Reduced costs.}

In the original consolidation project connections between the bracing system and the structure were made with threaded bars having a diameter of 16 with a pitch of $50 \mathrm{~cm}$.

In this case the connections are replaced with steel profiles with variable sections.

\section{Dissipative links}

The dissipation of seismic energy through the yielding process of steel elements has been studied by experimental approaches to evaluate the advantages of including this type of element in the structure.

The study conducted by Jun Jie Li in 2010 [21] is an interesting example: it investigates the interaction between heavy precast cladding units attached to steel framed buildings. Usually designed as non-structural components, the cladding system may be used to reduce the response of the primary structure under seismic actions with the insertion of flexible connections. In fact, the panels are usually bound at the primary structure with connections used to transfer the vertical load alone. These also restrict the movement of the panel. Tieback connections, instead, are flexible connections which only restrict out of plane deformation and allow vertical and horizontal displacements.

The hysteretic behaviour of the connection is inserted in the model with the aim of maximising the dissipated energy. This can reduce the damage of the primary structure during the seismic event.

The results show that by using elastic-plastic connections we obtain a reduction of the damage caused by the seismic action (between $96 \%$ and $100 \%$ ).

Another interesting study concerns the seismic consolidation of the "C. A. Pizzardi" Hospital (unit D) in Bologna [22].

The analysis concerns the structural dynamic assessment of the existing structure, composed of a central non-momentresisting steel frame characterized by a low horizontal stiffness, which supports essentially the vertical actions, and two external lateral-resisting elements of reinforced concrete (concrete cores) which mainly support the horizontal loads. The corresponding storeys of the two portions of the building (i.e. the frame structure and the lateral-resisting elements) are linked with specially-designed metallic sinusoidal elements (Figure 8).

The effectiveness of the elements has been valued considering two resistant sections M1 and M2: the element with section M2 has a double stiffness in comparison to the element of section M1.

At the beginning, the elements with a larger section (M2) are placed between the 1st and the 6th floor, and the elements with a smaller section (M1) between the 7th and the top floor. Various positions of the connecting elements were also tested to better investigate the contribution of these devices to the global response.

Non-linear dynamic time-history analyses were performed. Fig. 9 shows the comparison between the different link configurations.

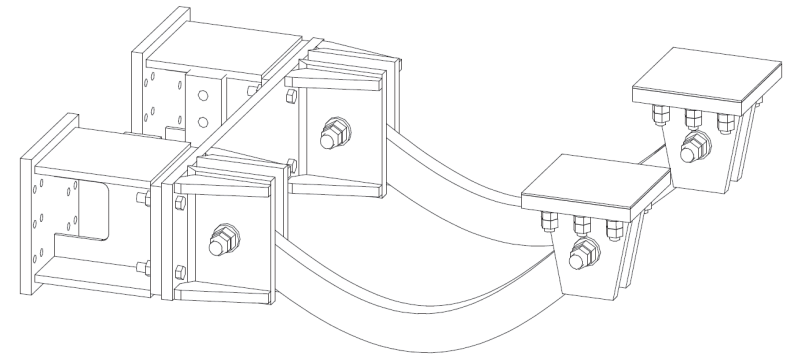

Figure 8: Axonometry of the connection between the frame structure and the lateral-resisting elements [22].

\section{Trend of shear at the base}

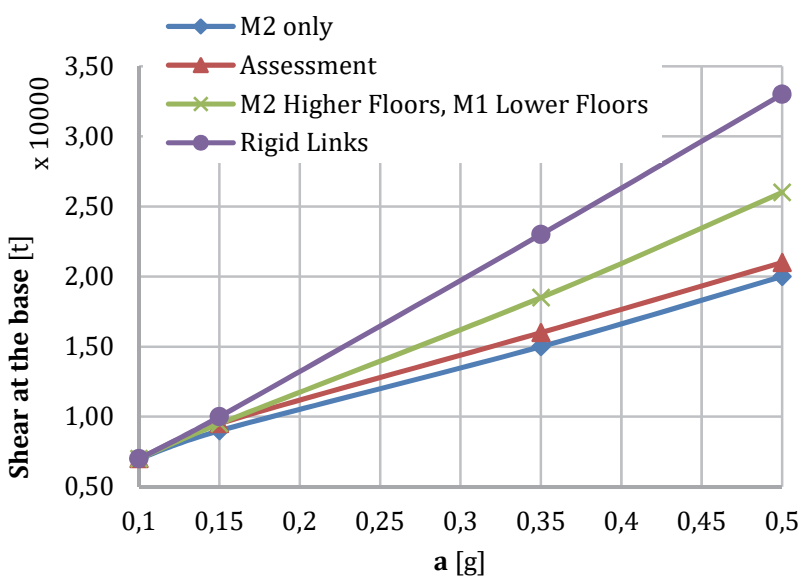

Figure 9: Trend of shear at the base: comparison of different types of height arrangement of connection links [22].

The study shows that the connection link arrangement affects the stress reduction factor. Considering the solution with M2 only, there is a $30 \%$ reduction of the stresses (shear) and, at the same time, there is not an excessive increase in relative displacements. 
For the primary school in Arcola, the connection between the building and the bracing system is made with commercial steel sections (Fig. 10) to minimize the cost.
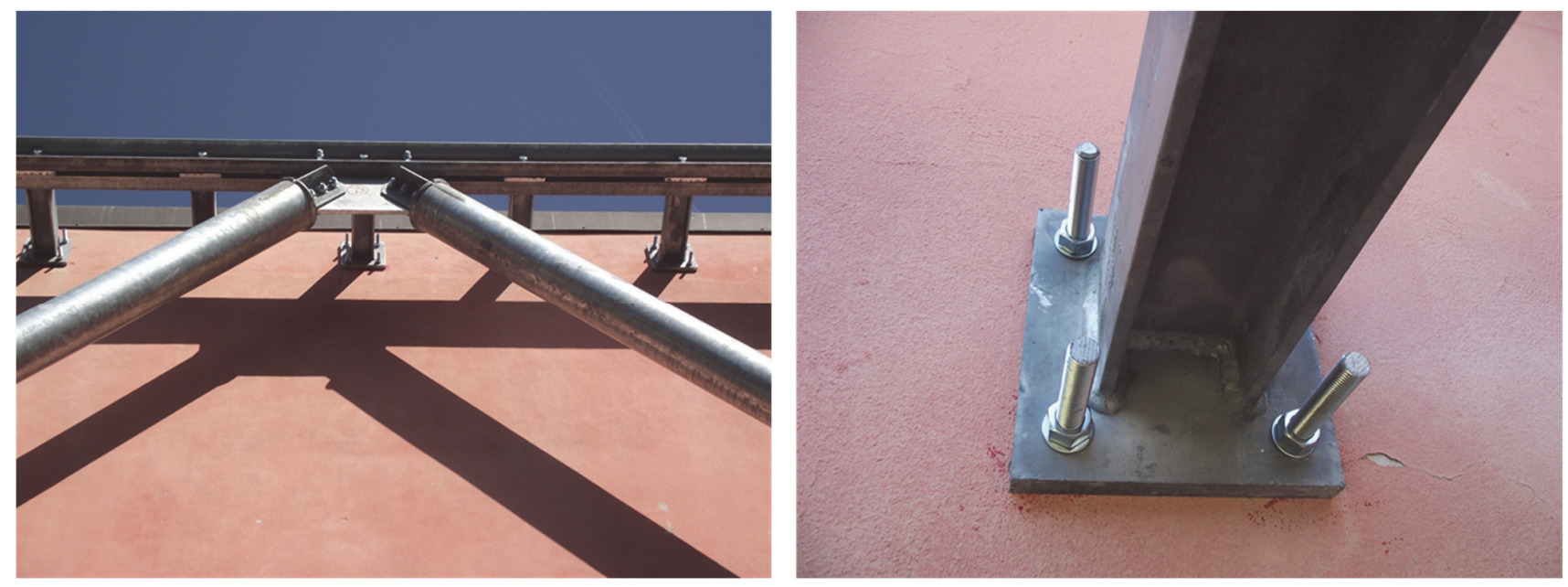

Figure 10: Example of deformable links (the school in Arcola). [16]

The steel profile is connected to the horizontal R.C. beam of the existing building thanks to a $10 \mathrm{~mm}$ thick plate with 4 M20 thread rod. The Profile (HEB120) is placed with the strong axis in the horizontal plane.

For the secondary school in Calcinaia, the building and the bracing system are connected by means of a R.C. slab made in SCC C40/50 and reinforcement $\Phi 16$ (Fig. 11)
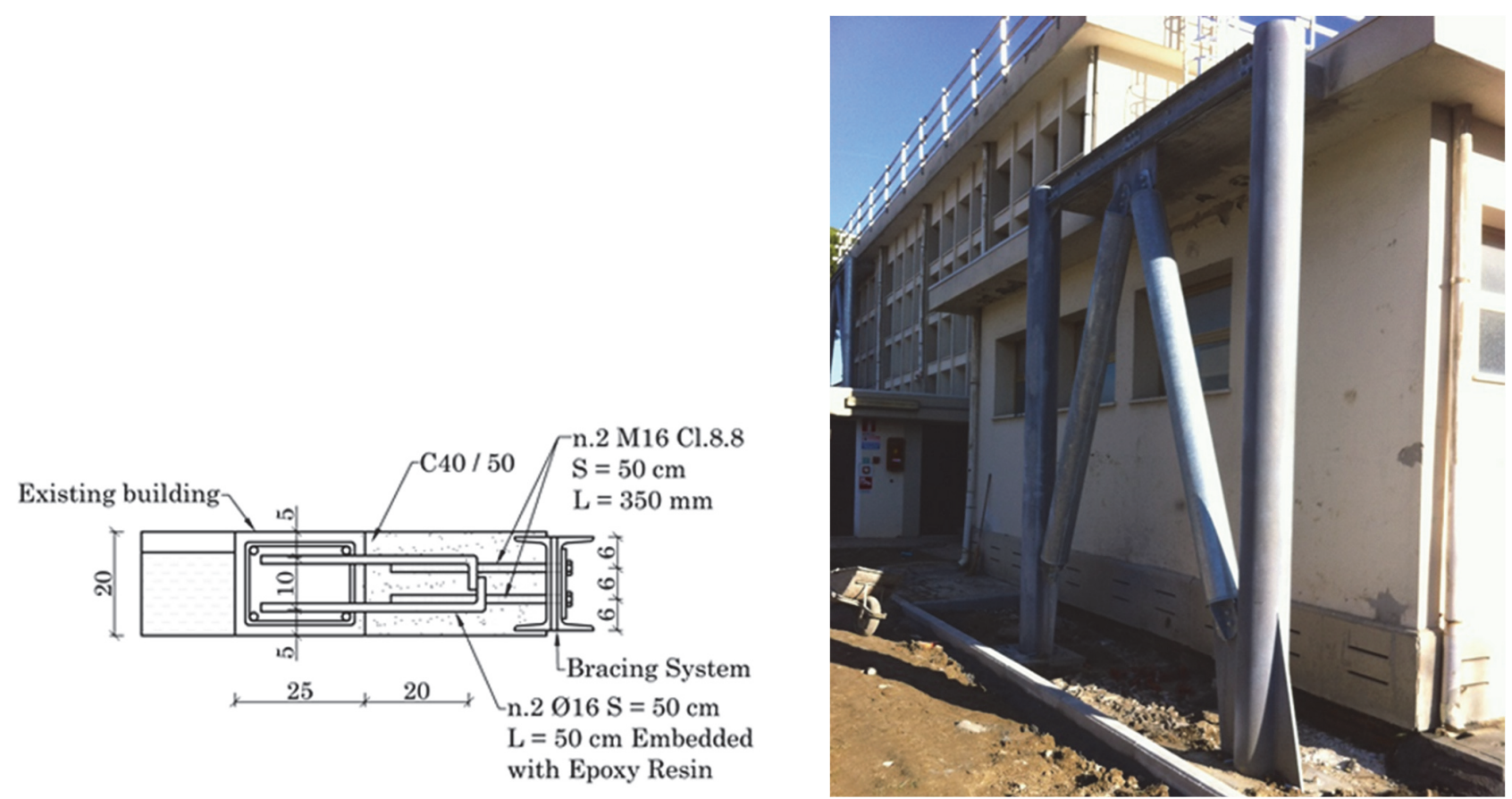

Figure 11: Example of rigid links (the school in Calcinaia). [20]

In the case of Arcola, the connection is flexible with dissipative capacity, due to the slenderness of the profiles (Fig. 10). In the case of Calcinaia the R.C. slab ensures a rigid connection with the bracing (Fig. 11). 


\section{A Case study}

T $\mathrm{n}$ this paper, the refurbishment of the "G. Carducci" school in Empoli (Firenze, Italy) is examined; the R.C. low rising structure is characterized by low-quality materials. Tab. 1 shows the strength of concrete and reinforcement used for this structure.

\begin{tabular}{ccc}
\hline & Concrete Class & Steel Class \\
Beams & R350 (C28/35) & FeB 44 \\
Columns & R300 (C25/30) & \\
\hline
\end{tabular}

Table 1: Materials

\section{The "G. Carducci" school in Empoli (Firenze, Italy)}

The building of the "G. Carducci" school in Empoli (Firenze, Italy) consists in a structure with plane frames in reinforced precast concrete, designed and built around 1972. The construction is a single structural unit consisting of two floors above ground (ground floor and first floor) [23].

The school is characterized by a rectangular central unit of two floors, approximately $24.0 \mathrm{~m} \times 22.0 \mathrm{~m}$ in size, to which two single floor unit (about $12.0 \mathrm{~m} \times 12.0 \mathrm{~m}$ ) are attached. There is also a technical annexe made of in-situ cast concrete) (Fig. 12, Fig. 13 and Fig. 14).

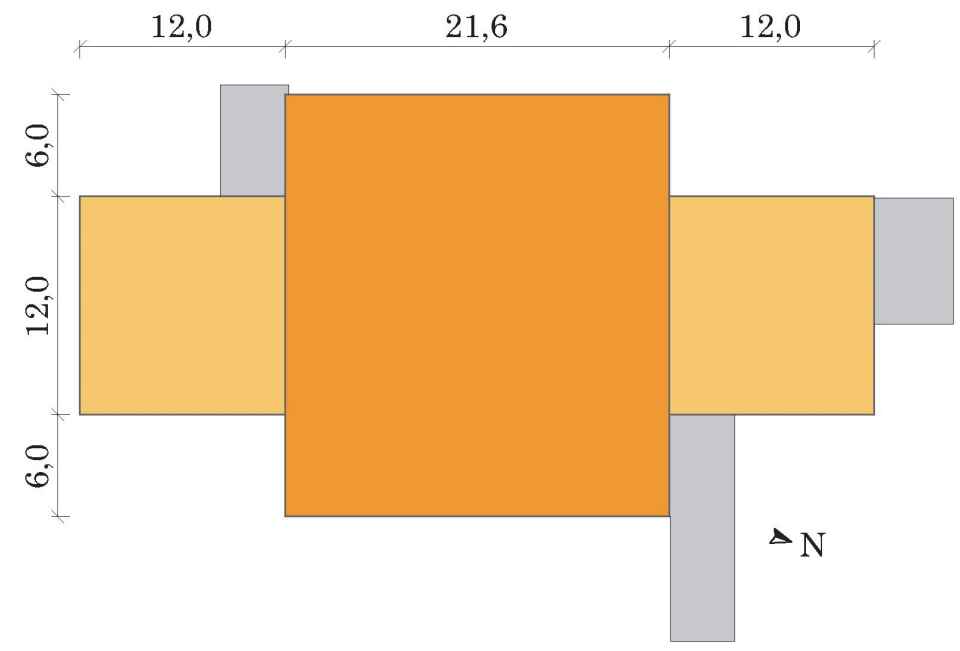

Sheds and technical annex, structurally independent

Ground Floor

First Floor

Figure 12: Schematic plan of the building. [23]

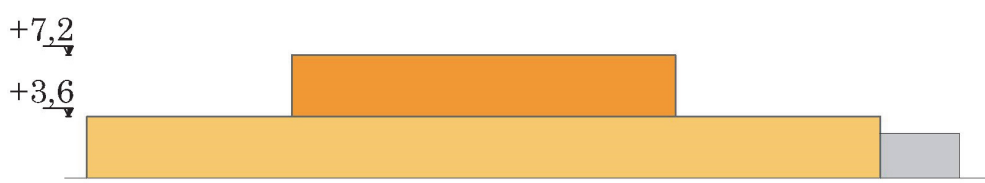

Sheds and technical annex, structurally independent

Ground Floor

$\square$ First Floor

Figure 13: Schematic front view of the building. [23] 


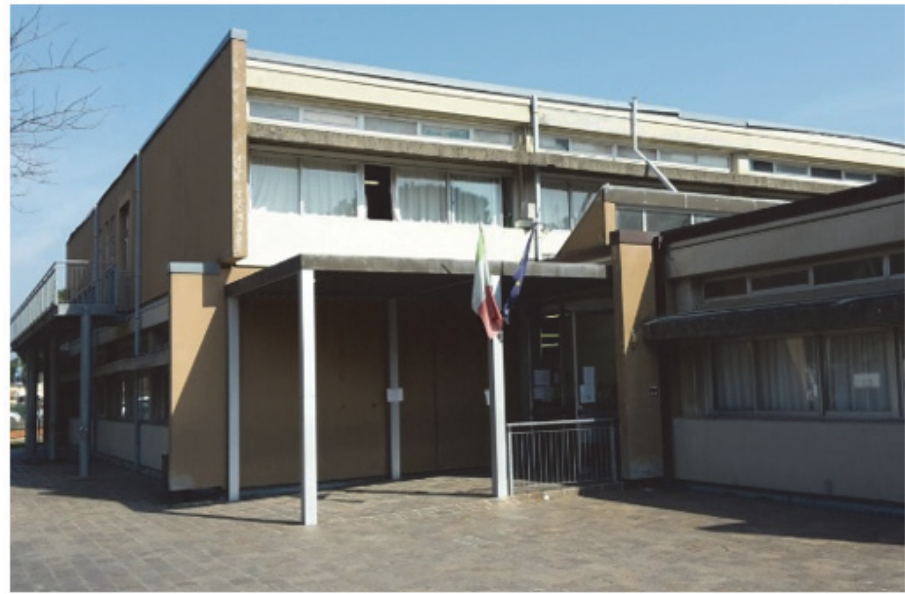

Figure 14: Southwest view, School entrance. [23]

Through the original design documents, it was possible to assess the material, the cross-section and the reinforcements corresponding to each structural element.

The building is characterized by a high seismic vulnerability; in fact, the structure is irregular in height and the beams are stronger than the columns (without respecting the hierarchy of resistance). The structure does not respond in a global way to seismic action (plane frames).

Therefore, consolidation is planned through an external bracing system.

4 inverted V-braces (Fig. 15 and Fig. 16) are provided in the $x$ direction and 4 in the $y$ direction.

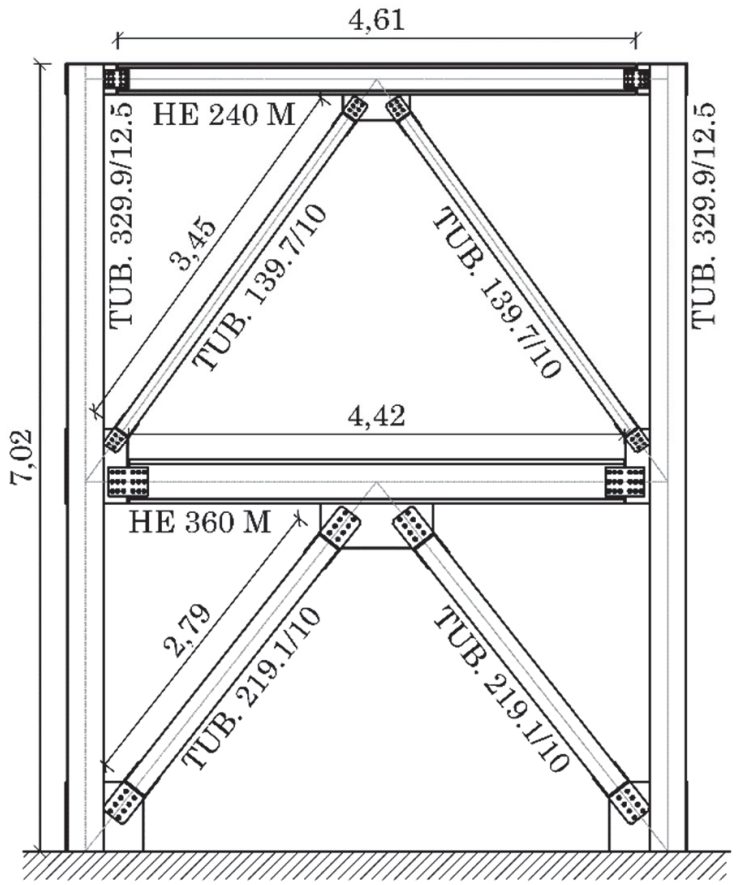

Figure 15: View of the inverted V-bracing system (Direction y).

The position of the bracing has been established considering the constraints imposed by the existing structure and the results of the vulnerability analysis of the building. The braces in the $x$ direction have been placed in the most critical areas, i.e. near the edge beams. For both directions, the authors have tried to keep the intervention outside the building.

Fig. 16 shows the plan disposition. 


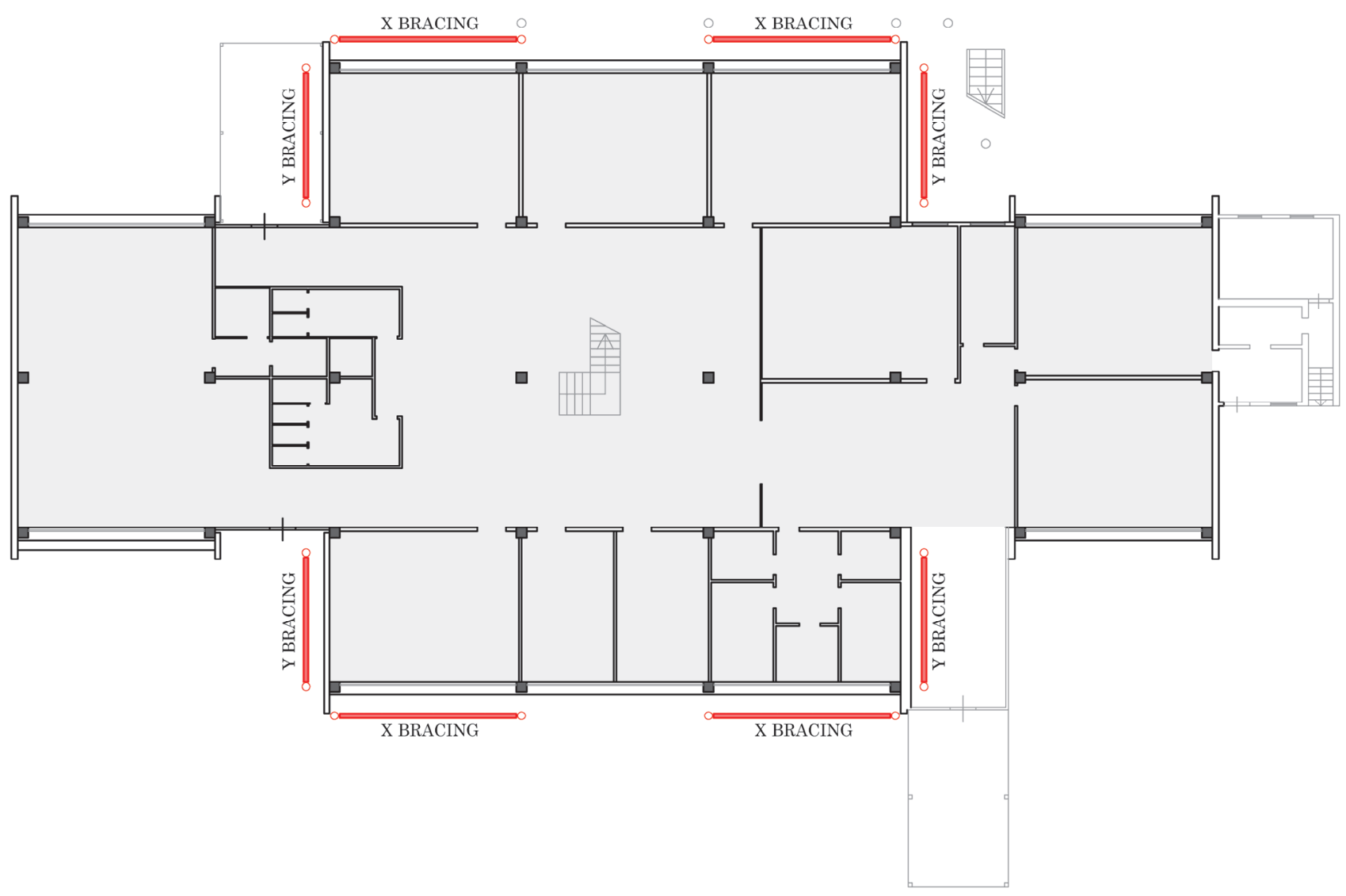

Figure 16: Plan disposition of the bracing system.

\section{DESIGN AND OPTIMIZATION}

s already mentioned, an external intervention presents a series of advantages:
$-\quad$ it avoids the demolition of existing structural parts;
it relieves the vertical resistant elements of the building from seismic action;

- $\quad$ it is easy to implement and not very invasive;

- it facilitates maintenance and integrity control.

The dissipation is obtained by exploiting the diagonal of the external bracing system.

By transmitting as much seismic action as possible to the external bracing it is possible to have two separate resistant systems: one for vertical actions (existing structure) and one for the horizontal actions (bracing system).

Even the connection between the building and the bracing system has stiffness and a dissipative capacity. So, although dissipative links are usually designed as special elements, it is also possible to evaluate the characteristic of dissipation of a traditional connection.

\section{Bracing system design}

The addition of an external bracing system aims to help the existing structural elements in withstanding the horizontal loads. In particular, the seismic action E consists of the following contributions (Fig. 17):

$$
\mathrm{E}=\mathrm{E}_{\mathrm{eb}}+\mathrm{E}_{\mathrm{nbs}}
$$

with:

E global seismic action;

$E_{\mathrm{eb}} \quad$ rate of action absorbed by the existing building (e.b.); 
$E_{\mathrm{nbs}} \quad$ rate of action absorbed by the new bracing system (n.b.s.).

It is well known that seismic action varies according to the stiffness of the structure and its natural period. Here it is assumed that $E$ is the maximum action calculated from the platean of the response spectrum.

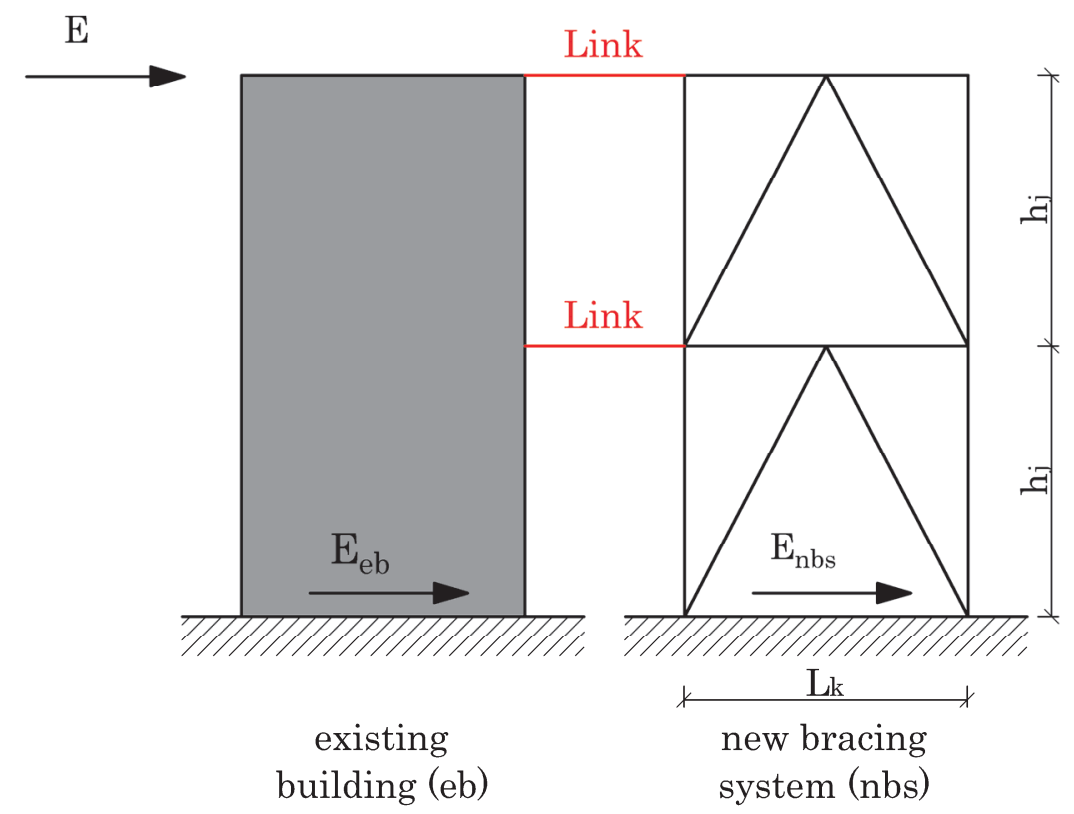

Figure 17: Distribution of the seismic action.

The target of the design is to ensure that $E_{\mathrm{nbs}}$ is higher than $E_{\mathrm{eb}}$.

To achieve this, the new bracing system (nbs) must have adequate stiffness with respect to the existing building (eb). In the hypothesis of a perfect connection between the two structures:

$$
\frac{E_{e b}}{K_{e b}}=\frac{E_{\text {nbs }}}{K_{\text {nbs }}}
$$

where:

$K_{\text {nbs }} \quad$ stiffness of the new bracing system;

$K_{\mathrm{eb}} \quad$ stiffness of the existing building.

As the capacity of the existing buildings $C_{\mathrm{eb}}$ is lower than of the global seismic action $E$, it is possible to calculate the action to transmit to (nbs) $E_{\text {nbs. }}$.

$$
\mathrm{E}_{\mathrm{nbs}}=\mathrm{E}-\mathrm{C}_{\mathrm{eb}}
$$

Subsequently it is possible to calculate the stiffness of the (nbs) to protect the (es) from the Eq. (2):

$$
\mathrm{K}_{\mathrm{nbs}}=\frac{\mathrm{E}_{\mathrm{nbs}}}{\mathrm{E}-\mathrm{E}_{\mathrm{nbs}}} \mathrm{K}_{\mathrm{eb}}
$$

It is possible to express this as follows:

$$
\mathrm{K}_{\mathrm{nbs}}=\alpha_{1} \mathrm{~K}_{\mathrm{eb}}
$$

Where $a_{1}$ is an over-stiffness factor. This factor must be higher than one, to ensure that the structure can be classifiable as braced [24]. This guarantees the respect of the Ultimate Limit State (ULS). 
The Damage Limitation State (DLS) can be obtained by ensuring that the maximum displacements are reduced. In the hypothesis of a rigid connection, it is:

$$
\Delta=\frac{\mathrm{E}^{\mathrm{DLS}}}{\mathrm{K}}
$$

where:

$\Delta$ maximum displacement limit imposed in [24].

From the Eq (6) it is possible to calculate the coefficient $a_{2}$, corresponding to DLS.

$$
\alpha_{2}=\frac{E}{\Delta K_{e b}}-1
$$

In order to guarantee the respect of both the limit states:

$$
\alpha=\max \left(\alpha_{1} ; \alpha_{2}\right)
$$

This allows the authors to design the bracing structure. In fact, from the equations:

$$
\mathrm{K}_{\mathrm{nbs}}=\alpha \mathrm{K}_{\mathrm{eb}}
$$

The comparison between the stiffness of the framed system and the bracing is carried out for the $j$-th floor of the structure without considering the collaboration of the infill wall.

To assess the stiffness of the existing building $K_{\mathrm{eb}}$, a shear-type frame model is developed as follows.

$$
\mathrm{K}_{\mathrm{eb}, \mathrm{j}}=\sum_{\mathrm{i}}^{\mathrm{n}_{\mathrm{i}}} \mathrm{k}_{\mathrm{i}, \mathrm{j}}
$$

With:

$K_{\text {eb,j }} \quad$ global stiffness of the $j$-th floor of the existing building;

$k_{\mathrm{i}, \mathrm{j}} \quad$ stiffness of the $i$-th column at the floor $j$;

$n_{\mathrm{j}} \quad$ number of columns on the $j$-th floor.

$k_{\mathrm{i}, \mathrm{j}} \quad$ is the composition of the bending stiffness and of the shear stiffness of the $i$-th column.

$$
\mathrm{k}_{\mathrm{i}, \mathrm{j}}=\frac{1}{\frac{\mathrm{h}_{\mathrm{j}}^{3}}{\mathrm{niEJ}_{\mathrm{i}, \mathrm{j}}}+\frac{\chi \mathrm{h}_{\mathrm{j}}}{\mathrm{GA} \mathrm{A}_{\mathrm{i}, \mathrm{j}}}}
$$

With:

$b_{j} \quad$ inter-floor height at the $j$-th level;

$J_{\mathrm{j}, \mathrm{j}} \quad$ moment of inertia in the $i$-th column;

$n_{\mathrm{j}} \quad$ coefficient that expresses the degree of constraint;

$A_{\mathrm{i}, \mathrm{j}} \quad$ cross-section area of the $i$-th column;

E Young modulus of concrete;

$G \quad$ shear modulus of concrete;

shear factor.

In the case of short element, the shear stiffness of the columns has a relevant role and cannot be neglected.

It is also possible to consider the stiffness of the (nbs) concentrated in the braces. To this end both diagonals have a structural role. (Fig. 18). 


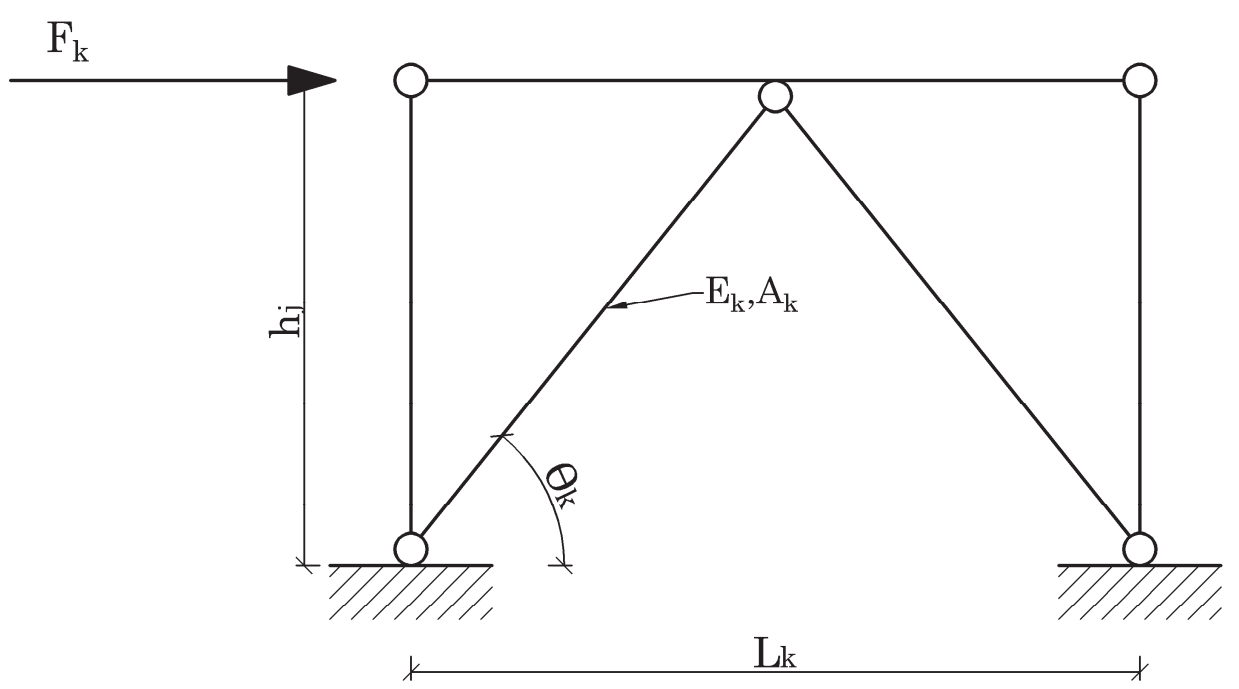

Figure 18: Static scheme for the evaluation of the single bracing stiffness

The global stiffness of the bracing system is given by the sum of the stiffnesses of the single bracing at the $j$-th level:

$$
\mathrm{K}_{\mathrm{nbs}, \mathrm{j}}=\sum_{\mathrm{k}}^{\mathrm{m}_{\mathrm{j}}} 2 \frac{\mathrm{E}_{\mathrm{k}} \mathrm{A}_{\mathrm{k}}}{\mathrm{L}_{\mathrm{k}}} \cdot \cos ^{2} \theta_{\mathrm{k}}
$$

with:

$K_{\mathrm{nbs}, j} \quad$ overall stiffness of the level $j$ of the new bracing system;

$E_{\mathrm{k}} \quad$ Young modulus of the $k$-th bracing at the $j$-th level;

$A_{\mathrm{k}} \quad$ area of the section of the diagonal for bracing $k$ in bracing level $j$;

$L_{\mathrm{k}} \quad$ length of the diagonal for bracing $k$ in bracing level $j$;

$\theta_{\mathrm{k}} \quad$ angle defined by the $k$-th diagonals and the horizontal at the $j$-th level.

From the Eqn. (9) it is possible to calculate the area of the cross-section of the bracing system $A_{k}$ fixing the value of $a$ as described.

Once $A_{k}$ has been calculated, it is possible to obtain the cross section of the frames of the bracing systems.

These considerations are useful to have a preliminary design of the elements that constitute the bracing system. In practice, the section of the elements $A_{k}$ was determined by attempts using Eqn. (12) (attempt values of the sections) and then enforcing Eqn. (9).

It is very important to ensure proper stiffness of the bracing systems for the following reasons:

- $\quad$ to guarantee compliance with the seismic code [24];

- $\quad$ to protect the structure not only towards the ULS but in particular towards the DLS.

This intervention can be optimized through the introduction of dissipative links.

The analyses carried out in the following paragraphs are based on an elastic design of the bracing system and modelling the seismic action through a linear static analysis.

In this way, the seismic action is overestimated in order to have a conservative design of the bearing elements. However, the optimization of the link system is obtained on the basis of a non-linear dynamic analysis.

\section{OPTIMIZATION OF THE LINK SYSTEMS}

$\mathrm{I}$

$\mathrm{n}$ the following paragraphs, an optimization of the link-bracing system is obtained on the basis of a non-linear dynamic analysis. 
In the previous paragraph, the ideal case of perfect connection between the existing structure and the new bracing system has been considered. In reality, this connection is not perfectly rigid. This imperfection in the transmission of actions between the two resistant systems can be amplified to obtain a seismic dissipation.

By modelling the actual stiffness of the connection (realized, as in this case, by means of circular hollow sections) it is possible to consider the dissipation provided by the links.

The more the stiffness of the connection decreases the more the actions acting on the external bracing are reduced. This allows an optimization of the consolidation system according to the effective loads.

In the following paragraph, the parameters governing the systems are analysed changing the links configuration. After that, an optimization of the systems composed by links and bracing is proposed and applied to a benchmark case.

\section{Parameters analysis}

It is observed that some variables dominate the design of the dissipative system:

(1) Relative stiffness of the bracing;

The stiffness of the braces is evaluated assuming a structural role for both diagonals (see Eq. (12)).

(2) Connection stiffness;

The overall stiffness of the single link is calculated, taking into account both the bending and the shear stiffness. It can be expressed by the following relation:

$$
\mathrm{K}_{\text {Link }}=\frac{1}{\frac{1}{\mathrm{~K}_{\mathrm{b}}}+\frac{1}{\mathrm{~K}_{\mathrm{s}}}}
$$

with:

$K_{\text {Link }} \quad$ overall stiffness of the single link;

$K_{\mathrm{b}} \quad$ bending stiffness of the single link;

Ks shear stiffness of the single link.

(3) Maximum displacements of the structure;

The inter-floor displacements $\left(\Delta_{1}\right.$ and $\left.\Delta_{2}\right)$ and the absolute displacement at the top of the structure $\left(\delta_{M A X}\right)$ are monitored (Fig. 19).

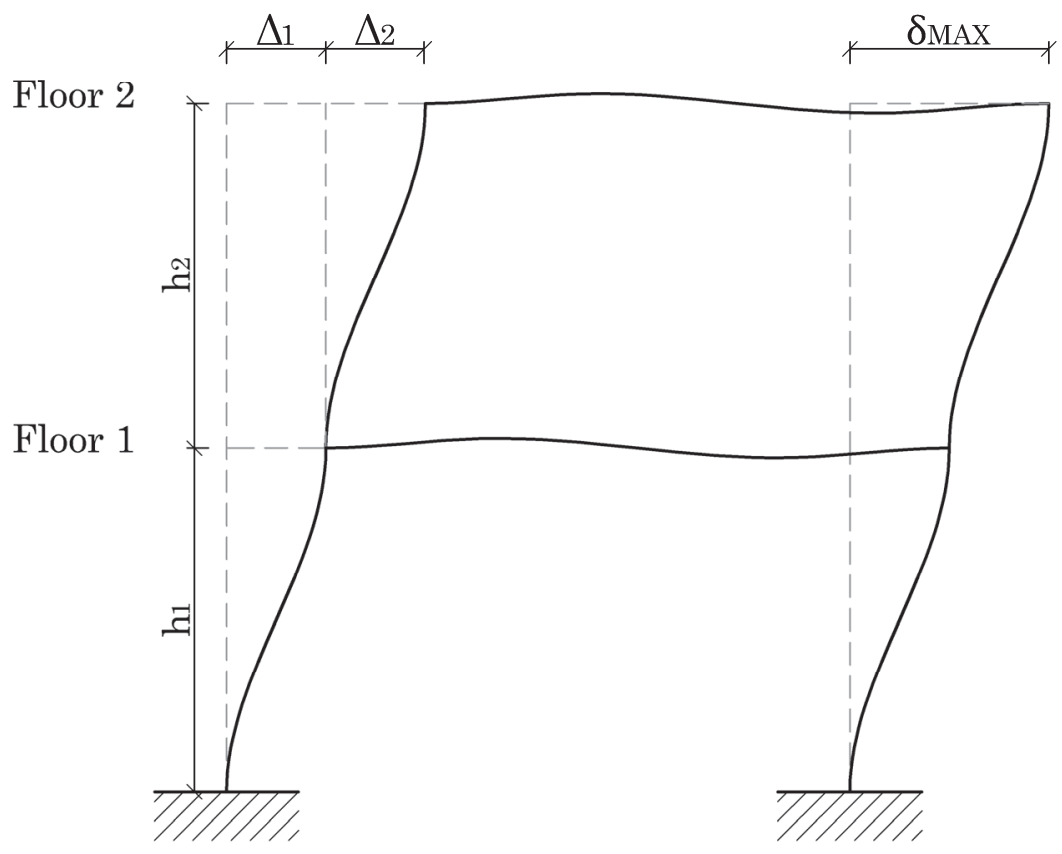

Figure 19: Displacement considered in the analysis.

The displacements have been normalized with respect to the inter-storey height and reported as a percentage for the sake of simplicity. 
As the link stiffness decreases, the maximum displacements of the existing structure are expected to increase.

(4) Maximum actions on the existing structure;

The proportion of seismic action absorbed by the existing structure and by the bracing system is controlled. In particular, the percentage of the shear at the base (see Fig. 17) of the existing columns is analysed.

$$
\mathrm{V}_{\mathrm{eb}, \mathrm{s} \%}=\frac{\mathrm{V}_{\mathrm{eb}, \mathrm{s}}}{\mathrm{V}_{\mathrm{s}}} \cdot 100
$$

with:

$V_{\text {ebs }, \%}$ percentage of shear at the base of the existing building for the planimetric direction $s(s$ can be $x$ or $y)$;

$V_{\mathrm{eb}, \mathrm{s}} \quad$ shear at the base of the existing building for direction $s(s$ can be $x$ or $y$ );

$V_{\mathrm{s}} \quad$ global shear at the base for direction $s$ (bracing and existing structure).

Obviously is:

$$
\mathrm{V}_{\mathrm{s}}=\mathrm{V}_{\mathrm{eb}, \mathrm{s}}+\mathrm{V}_{\mathrm{nbs}, \mathrm{s}}
$$

And consequently:

$$
\mathrm{V}_{\mathrm{nbs}, \mathrm{s} \%}=100-\mathrm{V}_{\mathrm{eb}, \mathrm{s} \%}
$$

As the stiffness of the links decreases, an increase of the seismic action on the existing structure is expected. In order to guarantee the effectiveness of the intervention the seismic action transferred to the brace must be at least $50 \%$ of the total value [24].

(5) Dissipation level.

Increasing the dissipation provided by the link decreases the action absorbed by the bracing system. Considering an elastic response of the bracing systems the dissipation is concentrated in the links.

The parameters described here are considered and integrated into the procedure described in the following paragraph.

\section{Optimization}

The procedure used for parametric analysis is described below:
(1) The bracing system is designed according to the stiffness.

As already mentioned, by comparing the stiffnesses (see Eq. (10) (12)), a bracing system is designed to absorb most of the seismic action.

(2) Dissipative links are modelled.

Starting from a rigid connection, the profiles chosen to make the connection are inserted into the model, gradually reducing their section. To guarantee the efficiency of the consolidation system, the percentage of the shear transmitted to the bracing system is at least $50 \%$.

(3) Linear and non-linear dynamic analyses are performed on the model.

For the linear dynamic analysis, the seismic action is defined through the response spectrum calculated according to [24].

For the non-linear dynamic analysis, the seismic action is modelled with a set of 7 artificial spectra-compatible accelerograms for each direction ( $\mathrm{x}$ and $\mathrm{y}$ ) generated with the software SIMQKE GR (Ver. 2.7)[25].

For the analyses carried out, the variation of the parameters (1-5) is considered and studied.

(4) Optimization of the retrofitting system.

Once a type of link has been established, by evaluating the decrease in the actions transmitted to the bracing system, it is possible to optimize the profiles of the retrofitting system. The process of optimization considers the more relevant parameters described above;

(5) Restart from point (2) until optimization is reached.

With new profiles, the procedure starts again from the second point until a suitably dimensioned, effective and economic bracing structure is obtained.

The procedure described here (Fig. 20) is applied to a Reduced Model of the Structure (RMS). 


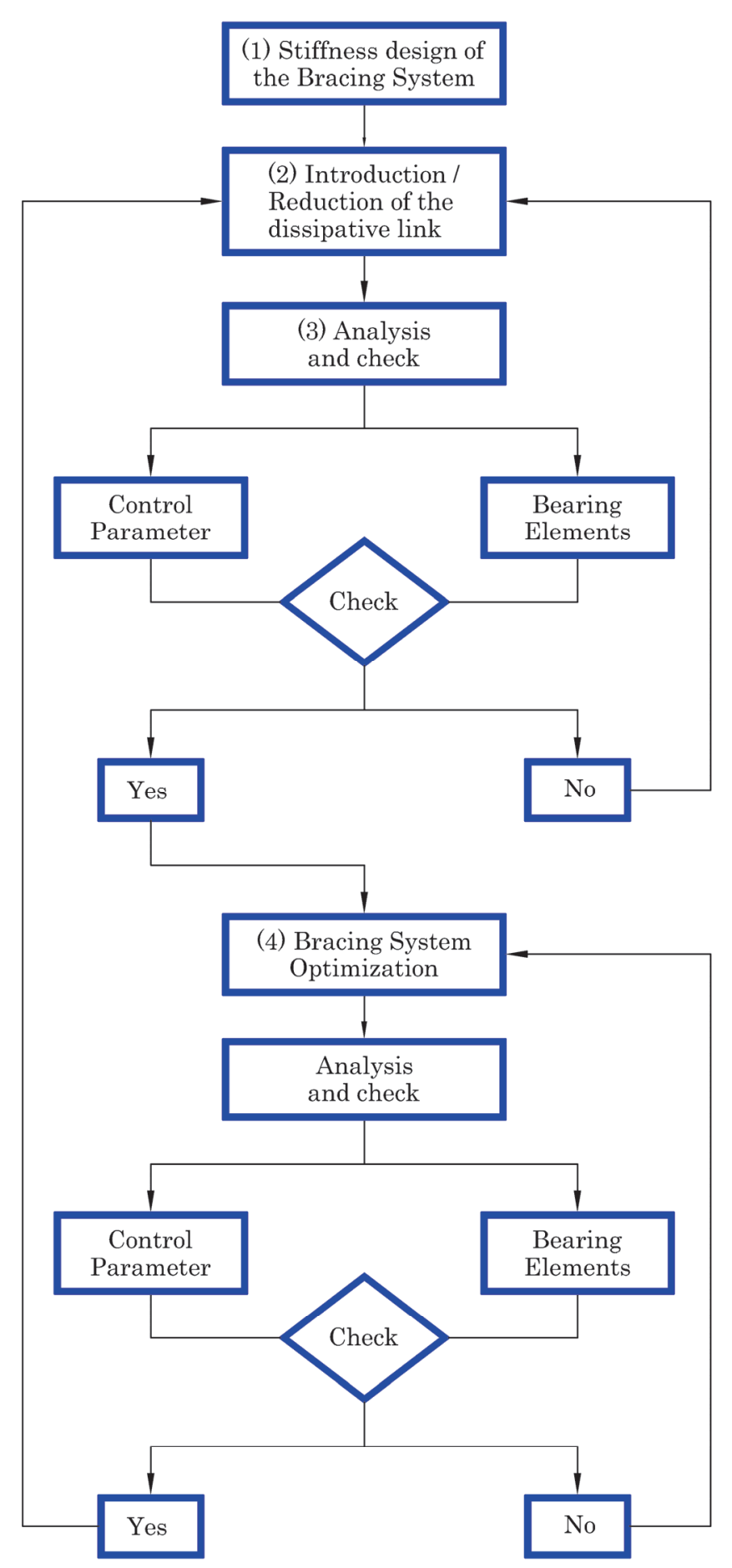

Figure 20: Procedure proposed.

\section{FEM ANALYSIS}

he procedure described above is applied to a portion of the "G. Carducci" School in Empoli. The effect of the link on ductility and dissipation is modelled through plastic hinges. In this case, the plastic hinge model described in the 1 FEMA code (Chapter 5 of [26]). Hence, flexural (ductile) and shear (brittle) plastic hinges are placed at the ends of the links. 
The diagonals of the (nbs) and the columns of the (es) are modelled with a linear-elastic behaviour.

Fig. 21 and Fig. 22 shows the properties of the flexural and shear plastic hinge defined in Sap2000 (Version 2017).

Frame Hinge Property Data

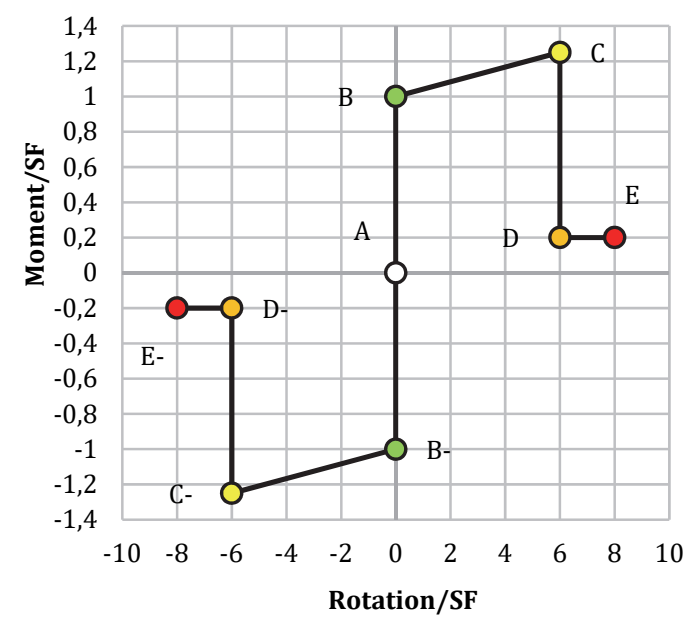

Figure 21: Properties of the flexural plastic hinge.
Frame Hinge Property Data

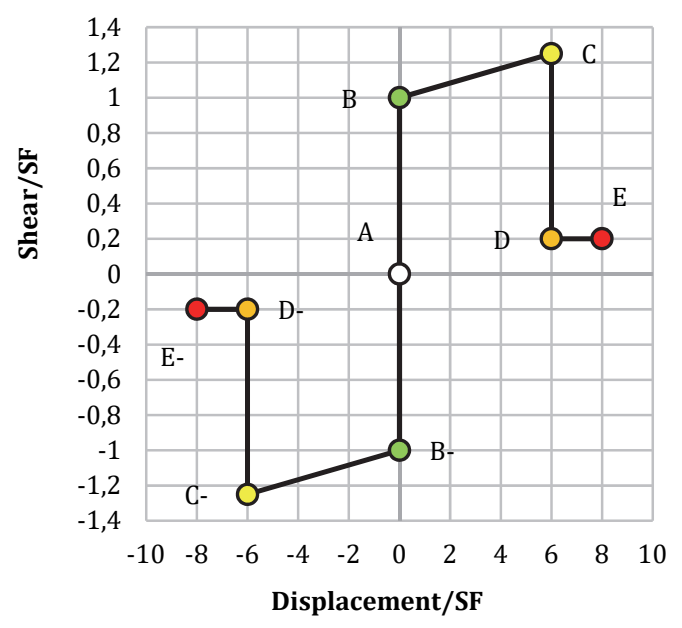

Figure 22: Properties of the shear plastic hinge.

\section{Preliminary study of links in series with Pushover Analysis}

In order to consider the effect of dissipation of the link systems the following parameters are significant:

- number and configuration;

- length (or eccentricity between mid-plane of the bracing system and side of the building);

- mechanical slenderness of the link;

- degree of restraint of the links.

First of all, a non-linear static analysis is carried out in Sap 2000 (Version 17) on a series of links as described in Fig. 23. The parameters of the link systems are: number of links equal to 10 , plastic hinge as extremity restraint. The beam that connects the extremity of the link is considered as rigid.

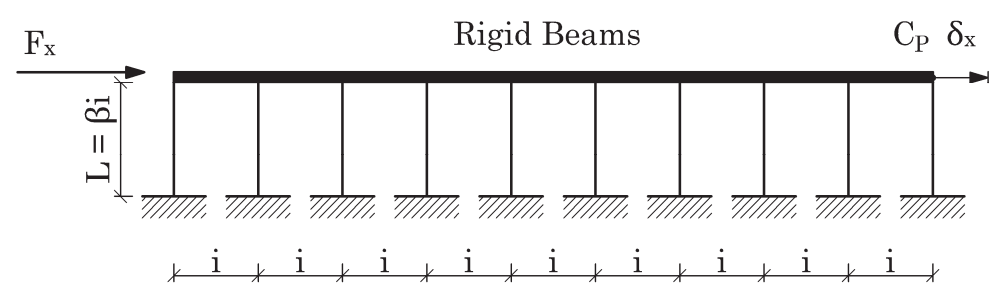

Figure 23: Scheme of the connection between existing buildings and new bracing systems. The geometrical parameters i and $\beta$ are here represented.

Sap 2000 allows the addition of a static horizontal load that can be increased up to the maximum displacement magnitude $(1 \mathrm{~m})$ of the control point. The main parameters chosen to perform the analyses are shown below:

- Maximum total steps per stage: 200;

- Maximum null steps per stage: 50;

- Maximum Newton-Raphson Iterations per step: 40;

- Iteration convergence tolerance (relative): 0.0001;

- Model characteristic: 20 points, 10 Frames.

The response of the system is analysed by varying the link length (that is the distance between the horizontal beam of the bracing system and the external side of the building), and the sections used for the link.

The results are shown in Tab. 2 and Tab. 3. Tab. 2 reports the length variation of the profiles while Tab. 3 presents the cross-section variation. Non-linear static analyses are carried out varying the link length or its cross section. In case of length 
variation, the type of the profile is fixed (steel tube with a diameter of $101.6 \mathrm{~mm}$ and a thickness of $6.3 \mathrm{~mm}-\mathrm{D} 101.6 \mathrm{~s} 6.3$ ). Instead, in case of variation of cross section the length of the link is fixed.

The length of the connections is assumed to be proportional to the interaxle spacing of the profiles:

$$
\mathrm{L}_{\text {Link }}=\beta \cdot \mathrm{i}
$$

With:

$\beta \quad$ coefficient that can vary from $1 / 4$ to 4 ;

$i \quad$ interaxle spacing of the profiles.

The coefficient $\beta$ determines the length of the link and its relative slenderness.

\begin{tabular}{ccc}
\hline & Length Variation & \\
Case & $\beta$ & $\mathrm{L}_{\text {Link }}[\mathrm{m}]$ \\
L1 & $1 / 4$ & 0.2 \\
L2 & $1 / 2$ & 0.4 \\
L3 & 1 & 0.8 \\
L4 & 2 & 1.6 \\
L5 & 4 & 3.2 \\
\hline
\end{tabular}

Table 2: Length variation - cases with fixed profile type (D 101.6 s 6.3)

\begin{tabular}{cc}
\hline \multicolumn{2}{c}{ Section Variation } \\
Case & Section \\
P1 & D 323.9 s 10 \\
P2 & D 193.7 s 8 \\
P3 & D 101.6 s 6.3 \\
P4 & D 76.1 s 5 \\
P5 & D 48.3 s 4 \\
\hline
\end{tabular}

Table 3: Section variation - cases with fixed length $\left(\mathrm{L}_{\mathrm{Link}}=0.8 \mathrm{~m} ; \beta=1\right)$

The graphs of the capacity curves obtained for the various models analysed are shown below (Fig. 24, Fig. 25 and Fig. 26).

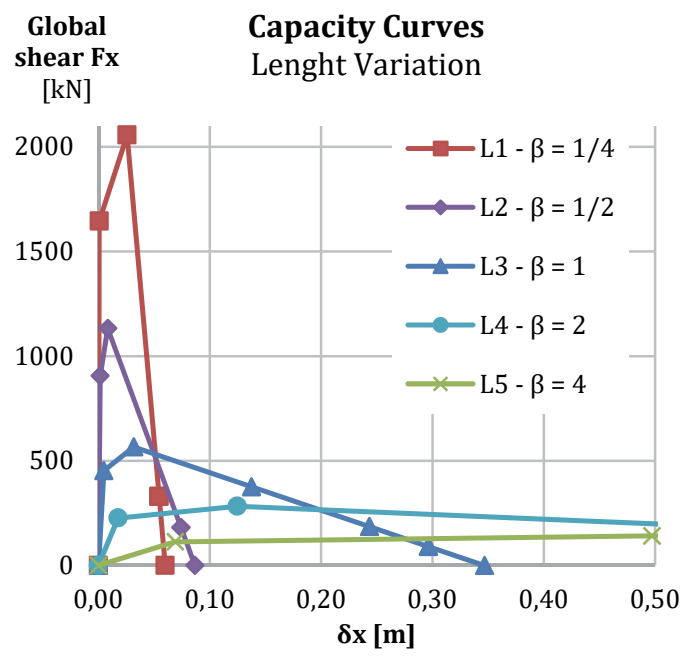

Figure 24: Capacity curves of the system of links - Length Variation. 


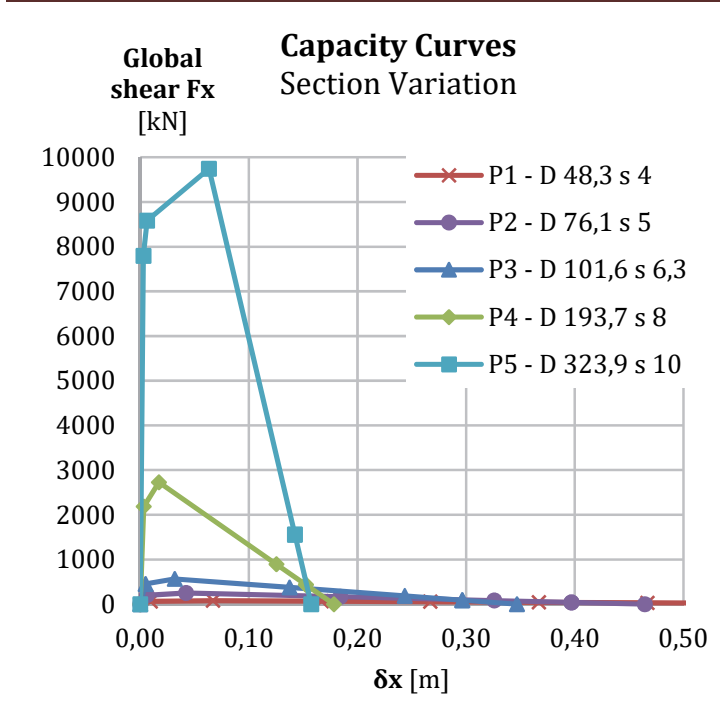

Figure 25: Capacity curves - Cross section Variation.

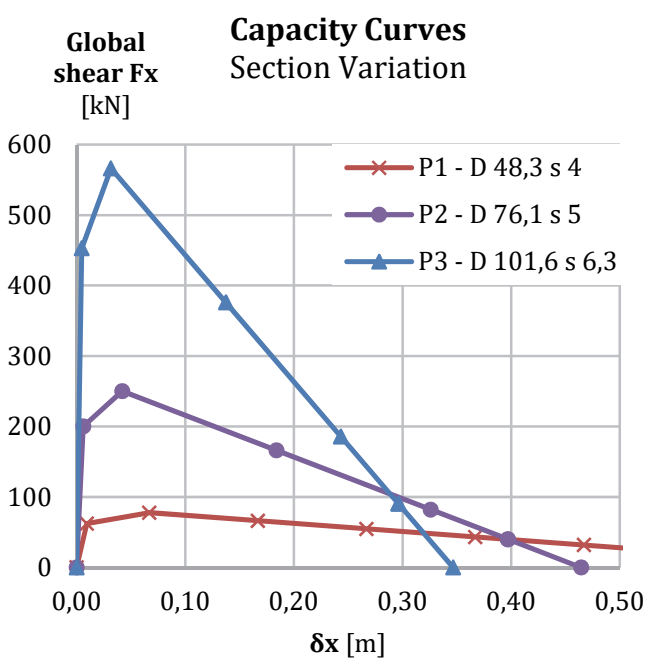

Figure 26: Capacity curves - Cross section Variation - P1, P2 and P3.

The graphs in Fig. 24, Fig. 25 and Fig. 26 show that the capacity of the link diverges significantly when varying the geometry of the links. This means that a different geometric configuration can produce a very different level of shear transmission and a very different level of dissipation. In this sense, the use of commercial profiles (instead of specific elements) can provide a useful opportunity to optimize the systems of the connection and of the bracing system.

\section{Parametric analysis of a connection system with dissipative links}

The goal is to act on the ductility of the system by introducing some dissipative links in the interface between bracings and buildings. An optimization of both link and bracing system is here proposed. Several analyses are performed in order to optimise the system.

A "simplified" and reduced model of the structure (RMS), with the same structural elements of the "G. Carducci" school, is created. For this reduced model some external inverted V-bracing are designed according to the criteria mentioned above. The RMS has the following plan dimensions: $14.4 \mathrm{~m}$ x $10.4 \mathrm{~m}$. The flexibility of the slabs is modelled through a pair of strut and tie systems as shown in Fig. 27.

In this first phase, a comparison is made between a hypothetical designed solution, in other words an external bracing with dissipative diagonals rigidly connected to the building, and various solutions obtained by gradually decreasing the stiffness of the connection, performing both linear and non-linear dynamic analyses.

The RMS of the "G. Carducci" has the same structural details (bearing beams, edge beams, columns and slab) as the original school.

There are two braces in the $x$ direction and two in the $y$ direction. A 3D model is implemented with Sap2000 software (Fig. 27).

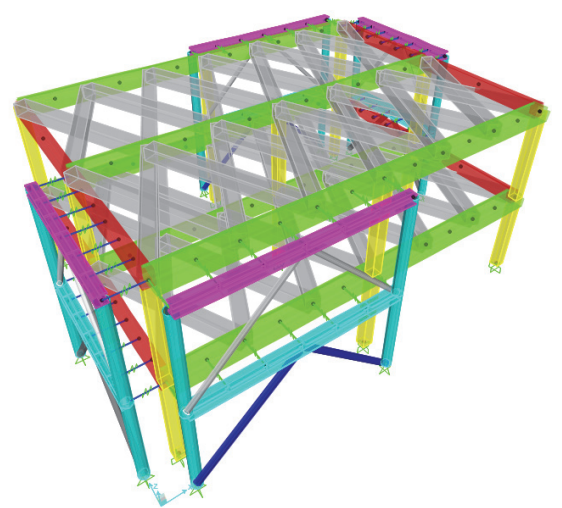

Figure 27: 3D “simplified” model - Sap2000.

The external bracing has been designed according to the indications provided in [24]. Tab. 4 shows the sections used for the bracing system (with reference to Fig. 28). 


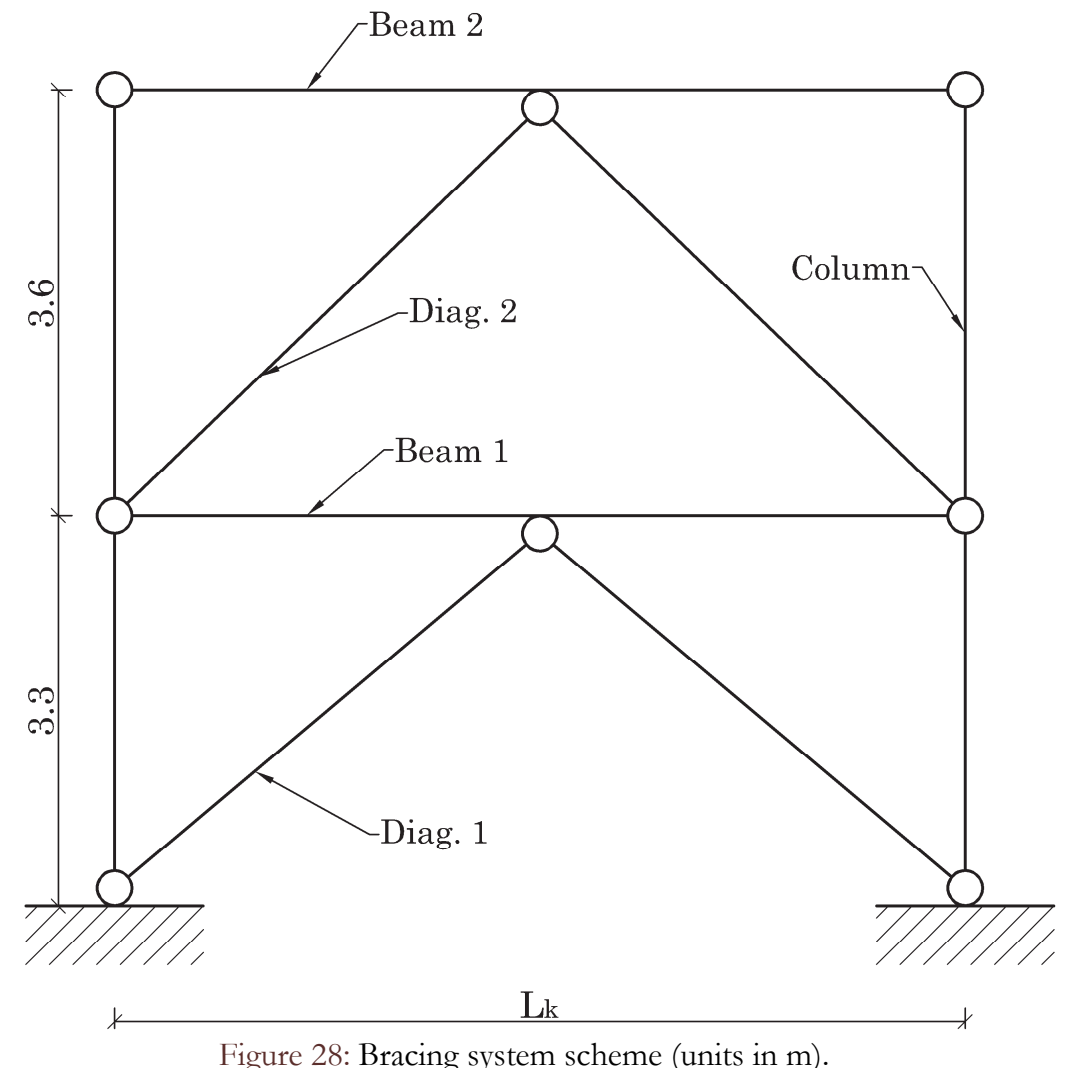

\begin{tabular}{ccc}
\hline & Case & Section \\
Column & D 355.6 s 10 & D $355.6 \mathrm{~s} 10$ \\
Beam 1 & HE $400 \mathrm{M}$ & HE $400 \mathrm{M}$ \\
Beam 2 & HE $300 \mathrm{M}$ & HE $300 \mathrm{M}$ \\
Diagonal 1 & D 219.1 s 10 & D $244.5 \mathrm{~s} 10$ \\
Diagonal 2 & D $168.3 \mathrm{~s} 10$ & D $168.3 \mathrm{~s} 10$ \\
$\mathrm{~L}_{\mathrm{k}}$ & $7.2 \mathrm{~m}$ & $5.2 \mathrm{~m}$ \\
$\mathrm{~h}_{1}$ & $3.3 \mathrm{~m}$ & $3.3 \mathrm{~m}$ \\
$\mathrm{~h}_{2}$ & $3.6 \mathrm{~m}$ & $3.6 \mathrm{~m}$ \\
\hline
\end{tabular}

Table 4: Bracing system

The connection between buildings and V-braces is made with 7 links (length $1.1 \mathrm{~m}$ ) for both directions.

The analysis starts with the study of a case called "Model Zero" (M0) in which each slab is rigidly connected to external bracing systems. This connection has been made with rigid link elements.

These elements are placed between the R.C. structure and the beams of the bracing elements.

The "Model Zero" (M0) is the reference point model.

It is important to underline that the floor of the structure has been modelled with a system of braces. The stiffness of the floor bracing is established following the method used for the analysis of the seismic vulnerability of the school of Empoli (FI) [23].

In the following step, the rigid connection is replaced with circular hollow steel sections. Both ends of the profile are continuous (no releases are modelled).

Thus 6 models are obtained, characterized by links with decreasing stiffness (Tab. 5). 


\begin{tabular}{cc}
\hline \multicolumn{2}{c}{ Section Variation } \\
Case & Section \\
M0 & Rigid \\
M1 & D 323.9 s 10 \\
M2 & D 244.5 s 8 \\
M3 & D 193.7 s 8 \\
M4 & D 139.7 s 7.1 \\
M5 & D 101.6 s 6.3 \\
\hline
\end{tabular}

Table 5: Analysed cases

Both linear and non-linear dynamic analyses were performed. For the linear dynamic analysis, the seismic action has been defined through the response spectrum calculated according to the [24].

Plastic hinges have been placed at the end sections of each link. The seismic action has been modelled with a set of 7 artificial spectra-compatible accelerograms for each direction ( $\mathrm{x}$ and $\mathrm{y}$ ) generated with SIMQKE GR software (Ver. 2.7)[25]

The direct integration of equilibrium equations is the most general approach to determine the dynamic response of a structure; this means satisfying the motion equations in a discrete number of time intervals by means of a special algorithm. However, the structures generally have a limited number of elements in the non-linear field during an earthquake.

This number drops considerably for structures with dissipative elements, keeping the response of the remaining part of the structural organism essentially in the elastic field, as in the case in question.

In these cases, it is advisable to avoid a non-linear analysis approach with direct integration of the equations of motion, whose resolution process provides for the updating of the stiffness matrix at each integration step.

The alternative, valid for models with concentrated non-linearity, is called "Fast Non-linear Analysis" (FNA).

In this approach, at each integration step, only the response of the nonlinear elements is subjected to an incremental-iterative procedure, while for the larger part of the structure (characterized by an elastic-type response) the stiffness matrices remain unchanged.

In this case, Sap2000 allows the authors to transform the applied plastic hinges to non-linear link (NL-Link). This allows the use of FNA analysis, which considerably reduces the processing times for the analyses carried out. The main parameters chosen to perform dynamic non-linear analyses are shown below:

- Number of output time steps: 2500;

- Force convergence tolerance (relative): 0.00001;

- Maximum iteration limit: 100;

- Minimum iteration limit: 2;

- Convergence factor: 1 ;

- Model characteristic: 175 points, 250 frames, 56 links.

First of all, the results of modal analyses with the models M0-M5 are examined. The proper periods of the structure and the percentage of participant mass for the first two eigenmodes are obtained (Tab. 6).

\begin{tabular}{ccccc}
\hline Case & \multicolumn{2}{c}{ Proper Periods } & \multicolumn{2}{c}{ Participant Mass } \\
& $\mathrm{T}_{1}[\mathrm{~s}]$ & $\mathrm{T}_{2}[\mathrm{~s}]$ & $\% \mathrm{Y}$ & $87 \%$ \\
M0 & 0.171 & 0.158 & $87 \%$ & $90 \%$ \\
M1 & 0.180 & 0.166 & $88 \%$ & $91 \%$ \\
M2 & 0.188 & 0.174 & $88 \%$ & $91 \%$ \\
M3 & 0.199 & 0.185 & $89 \%$ & $91 \%$ \\
M4 & 0.232 & 0.216 & $89 \%$ & $90 \%$ \\
M5 & 0.291 & 0.270 & $88 \%$ & \\
\hline
\end{tabular}

Table 6: Modal Analysis Results 
The percentage of base share absorbed by the existing structure is determined (Tab. A.1. 1, Appendix).

Fig. 29 and Fig. 30 present the trend of the percentage of shear at the base of the structure on the stiffness of the connecting elements.

For the sake of simplicity, in the graphic representation the stiffness of the link has been normalized with respect to the link with higher stiffness.

The limit shear at the base of the existing structure (50\%) is represented with a dotted red line.

Shear at the base of the (eb)

\%Veb,x $\mathrm{X}$ Direction

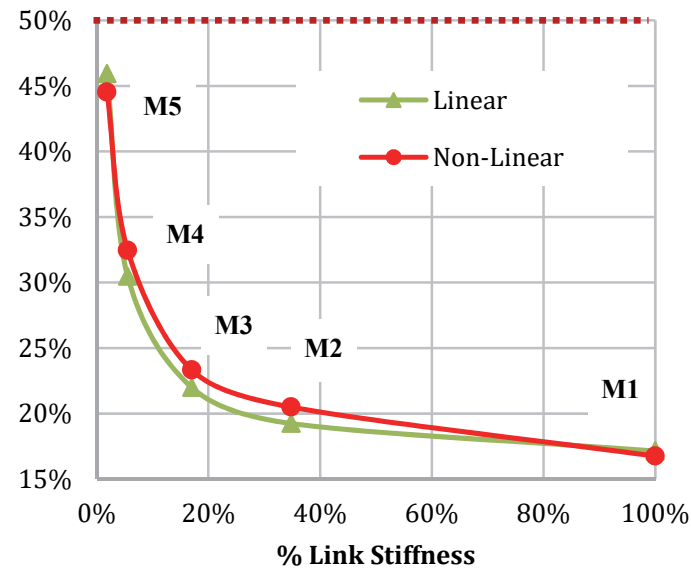

Figure 29: Trend of share at the base of the existing structure on the relative stiffness of the connecting elements - X Direction.

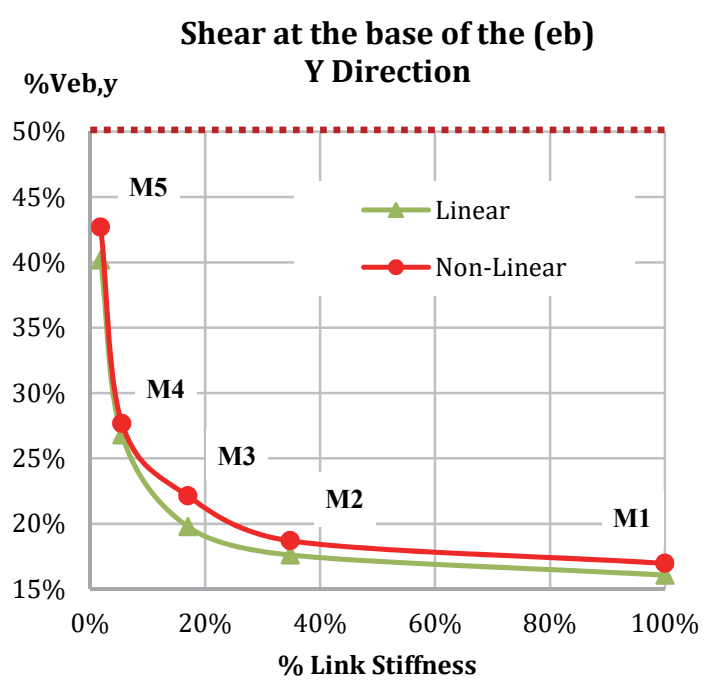

Figure 30: Trend of share at the base of the existing structure on the relative stiffness of the connecting elements - Y Direction.

The shear at the basement of the existing buildings $V_{\text {eb }}$ decreases when the stiffness of the connections is increased.

Moreover, comparing the results of the analyses for the two directions (Fig. 31), it is possible to notice a similar behaviour. Reducing the stiffness of the links also decreases the shear transmitted to the new bracing system $V_{\text {nbs. }}$ This allows a more economic and rational optimization of the sections.

All the link configurations chosen here are acceptable because the shear at the base of the existing structure is under the $50 \%$ limit.

The introduction of links of different stiffness also affects the structural response of the existing building. When this happens, therefore, the irregularities of the existing building can be compensated.

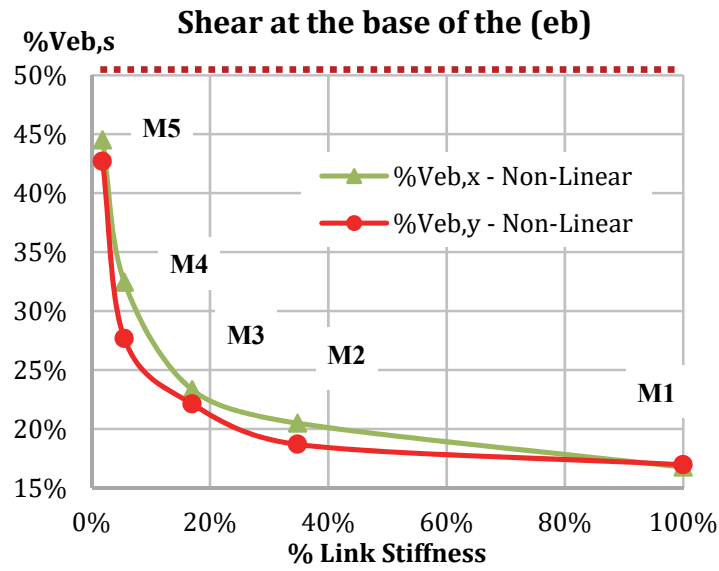

Figure 31: Trend of share at the base of the existing structure on the relative stiffness of the connecting elements - Y Direction.

The inter-floor displacements $\left(\Delta_{1}\right.$ and $\left.\Delta_{2}\right)$ and the absolute displacement at the top of the structure ( $\left.\delta_{\text {MAx }}\right)$ for the OLS (Operative Limit State defined by the Italian Code [24]) are also monitored (see Fig. 19). 
For inter-floor displacement the standard requirements are:

$$
\begin{aligned}
& \Delta_{1}<0,003 \cdot \mathrm{h}_{1} \\
& \Delta_{2}<0,003 \cdot \mathrm{h}_{2}
\end{aligned}
$$

$h_{1}, h_{2} \quad$ inter-floor height.

All detected displacements satisfy the verification. The following images (Fig. 32, Fig. 33, Fig. 34) show the trend of the displacements obtained from linear and non-linear analysis of the connecting elements. The graphs were normalized with respect to the height of the ground floor $\left(\mathrm{h}_{1}=3.3 \mathrm{~m}\right)$ and reported in percentage.

The limit ratio between displacement and inter-storey height is represented with a dotted/dashed red line.

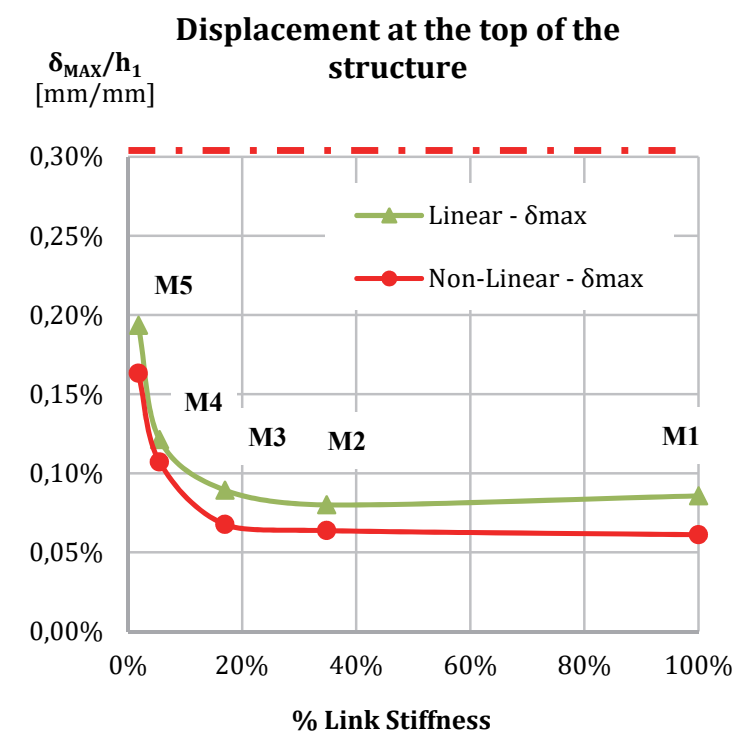

Figure 32: Trend of the absolute displacement at the top of the structure on the relative stiffness of the connecting elements.

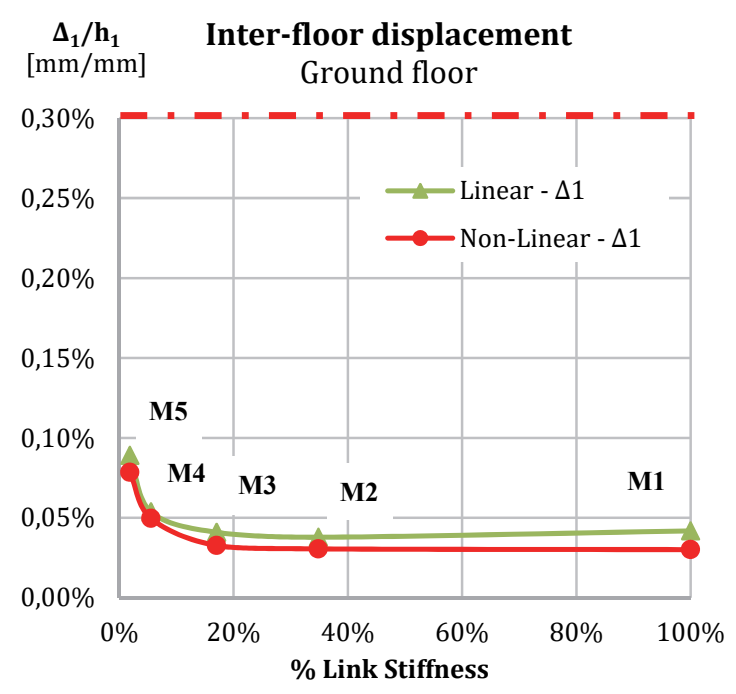

Figure 33: Trend of the inter-floor displacement on the relative stiffness of the connecting elements - Ground floor.

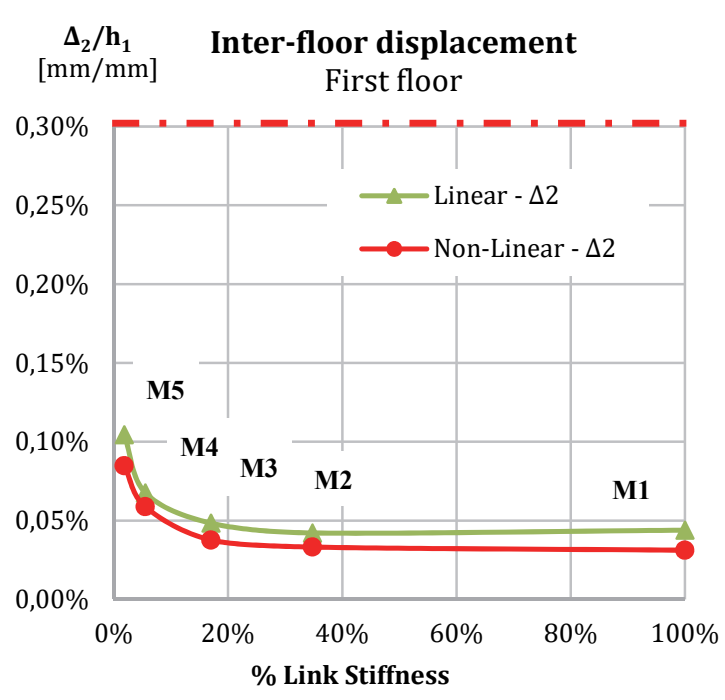

Figure 34: Trend of the inter-floor displacement on the relative stiffness of the connecting elements - First floor.

Moreover, the behaviour of the links themselves is analysed with the aim of evaluating what is the collapse mode of the links.

In this way, it is possible to check if there is a ductile failure and plastic hinges must be placed at the ends of the steel profiles. 
The three main collapse modes are evaluated: (1) Biaxial bending collapse; (2) Shear collapse and (3) achievement of the rotational capacity.

(1) Biaxial flexural collapse - Ductile collapse;

$$
\frac{\mathrm{M}_{x, \mathrm{Ed}}}{\mathrm{M}_{\mathrm{x}, \mathrm{Rd}}}+\frac{\mathrm{M}_{\mathrm{y}, \mathrm{Ed}}}{\mathrm{M}_{\mathrm{y}, \mathrm{Rd}}} \leq 1
$$

With:

$M_{\mathrm{x}, \mathrm{Ed}}$ and $M_{\mathrm{y}, \mathrm{Ed}}$ bending moment demand;

$M_{\mathrm{x}, \mathrm{Rd}}$ and $M_{\mathrm{y}, \mathrm{Rd}}$ bending moment capacity;

(2) Shear collapse - brittle collapse.

$$
\frac{V_{x, E d}}{V_{x, R d}}+\frac{V_{y, E d}}{V_{y, R d}} \leq 1
$$

With:

$V_{\mathrm{x}, \mathrm{Ed}}$ and $V_{\mathrm{y}, \mathrm{Ed}}$ bending moment demand;

$V_{\mathrm{x}, \mathrm{Rd}}$ and $V_{\mathrm{y}, \mathrm{Rd}}$ bending moment capacity;

(3) Achievement of the ultimate rotational capacity.

$$
\frac{\Theta_{\mathrm{Ed}}}{\Theta_{u}} \leq 1
$$

With:

$\theta_{\text {Ed }} \quad$ rotational demand;

$\theta_{\mathrm{u}} \quad$ rotational capacity.

The results obtained from the analyses are reported below (Tab. A.1. 4, Tab. A.1. 5, Appendix).

It should be noted that in all cases the links never exceed the ultimate capacity or the shear capacity. The trend of the ratio between biaxial demand and capacity (1) is shown below (Fig. 35). When this ratio exceeds the unit value, it means that a flexural plastic hinge has been formed in the connection.

The limit condition for the plastic hinge formation is represented with a dashed red line.

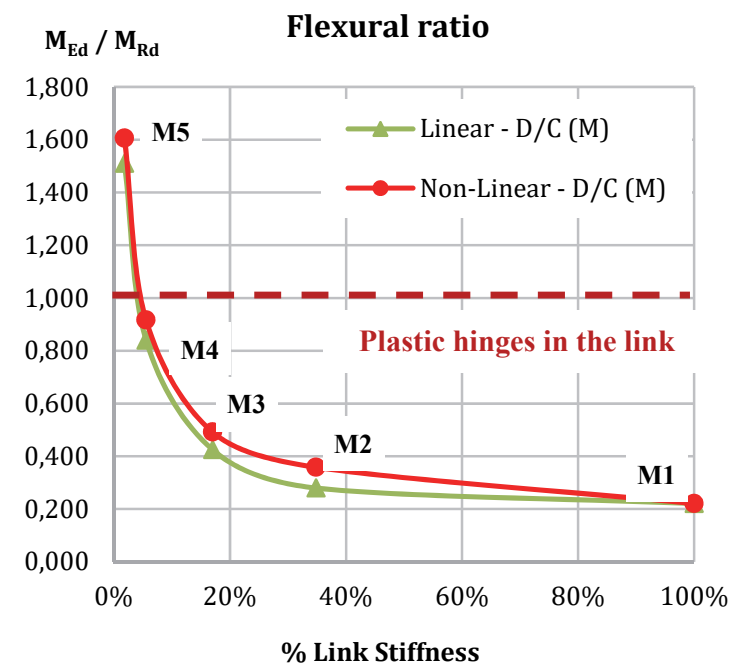

Figure 35: Trend of the ratio between flexural demand and capacity on the relative link stiffness.

Optimization of the Bracing System

In the previous paragraph the most relevant geometric and mechanical parameters have been analysed for bracing systems and connecting elements. 
In particular, the braces have been designed assuming a rigid connection and the cross sections of the selected profiles have been not modified in the analysed models.

Subsequently the cross sections of the bracing systems are reduced and consequently the cross sections of the links are also modified.

Four types of bracing are defined, obtained by gradually decreasing the size of their cross-sections, as shown in Tab. 7.

\begin{tabular}{|c|c|c|c|c|c|}
\hline & & Brace type A & Brace type B & Brace type $\mathrm{C}$ & Brace type D \\
\hline \multirow{5}{*}{ 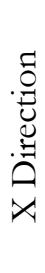 } & Column X & D $355.6 \mathrm{~s} 10$ & D 323.9 s 10 & D $244.5 \mathrm{~s} 10$ & D $219,1 \mathrm{~s} 10$ \\
\hline & Beam $1 \mathrm{X}$ & $\mathrm{HE} 400 \mathrm{M}$ & $\mathrm{HE} 400 \mathrm{M}$ & HE $320 \mathrm{M}$ & HE $280 \mathrm{M}$ \\
\hline & Beam $2 X$ & $\mathrm{HE} 300 \mathrm{M}$ & HE $300 \mathrm{M}$ & $\mathrm{HE} 240 \mathrm{M}$ & HE $200 \mathrm{M}$ \\
\hline & Diagonal $1 \mathrm{X}$ & D $219.1 \mathrm{~s} 10$ & D $219.1 \mathrm{~s} 10$ & D $168.3 \mathrm{~s} 10$ & D $139,7 \mathrm{~s} 10$ \\
\hline & Diagonal $2 \mathrm{X}$ & D $168.3 \mathrm{~s} 10$ & D $168.3 \mathrm{~s} 10$ & D 139.7 s 10 & D $114,3 \mathrm{~s} 10$ \\
\hline \multirow{5}{*}{ 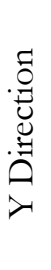 } & Column Y & D 355.6 s 10 & D 323.9 s 10 & D $244.5 \mathrm{~s} 10$ & D $219,1 \mathrm{~s} 10$ \\
\hline & Beam 1 Y & $\mathrm{HE} 400 \mathrm{M}$ & $\mathrm{HE} 400 \mathrm{M}$ & HE $320 \mathrm{M}$ & HE $280 \mathrm{M}$ \\
\hline & Beam 2 Y & HE $300 \mathrm{M}$ & $\mathrm{HE} 300 \mathrm{M}$ & $\mathrm{HE} 240 \mathrm{M}$ & HE $200 \mathrm{M}$ \\
\hline & Diagonal $1 \mathrm{Y}$ & D $244.5 \mathrm{~s} 10$ & D 219.1 s 10 & D 168.3 s 10 & D 139,7 s 10 \\
\hline & Diagonal $2 \mathrm{Y}$ & D $168.3 \mathrm{~s} 10$ & D 168.3 s 10 & D 139.7 s 10 & D 114,3 s 10 \\
\hline \multicolumn{2}{|c|}{ Tot. weight $[\mathrm{kN}]$} & $103.38 \mathrm{kN}$ & $100.58 \mathrm{kN}$ & $79.85 \mathrm{kN}$ & $61.89 \mathrm{kN}$ \\
\hline
\end{tabular}

Table 7: Bracing types

To speed up the procedure, dynamic linear analyses have been performed. The comparison between linear dynamic and non-linear dynamic shows that the difference between the results is reduced. Linear dynamic analysis can be used in the optimization process.

The weight of steel for each type is shown in Tab. 7 and it decreases from brace type A to brace type D. The weight is proportional to the cost of the retrofitting system. It is therefore an indicator of the economic savings obtained with this type of optimization (about $42 \%$ for these cases).

In the following graphs the parameter of the curves is the bracing type (from A to D) while the point represents the kind of links analysed.

In Fig. 36 and Fig. 37 the trend of the percentage of shear at the base of the structure on the stiffness of the connecting elements is presented.

The limit shear at the base of the existing structure (50\%) is represented with a dotted red line.

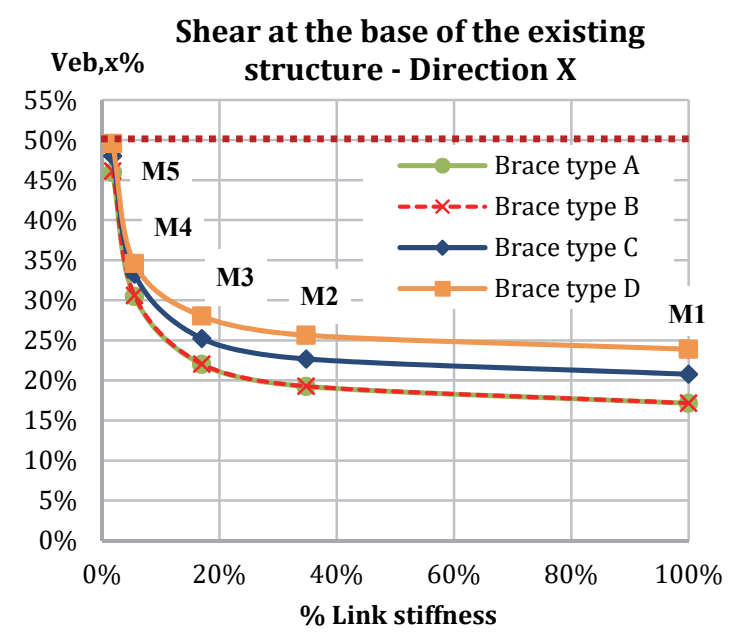

Figure 36: Trend of share at the base of the existing structure on the relative stiffness of the connecting elements - Direction X.

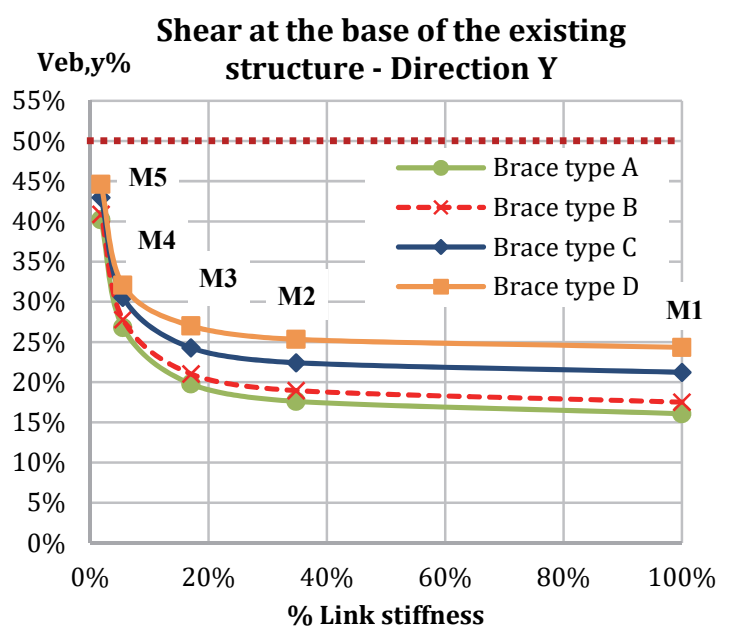

Figure 37: Trend of share at the base of the existing structure on the relative stiffness of the connecting elements - Direction Y. 
The percentage of shear absorbed by the brace system decreases as the stiffness of both brace and links decreases. The shear at the base absorbed by the bracing never falls below 50\%. The inter-floor displacements $\left(\Delta_{1}\right.$ and $\left.\Delta_{2}\right)$ and the absolute displacement at the top of the structure $\left(\delta_{\mathrm{MAx}}\right)$ to the OLS are monitored (Fig. 38, Fig. 39 and Fig. 40). For these analyses all the displacements satisfy the verification imposed by the Italian code $(\Delta / \mathrm{h}<1 / 300)$ [24]. As the stiffness of the connection and the brace system decreases, the displacements of the existing structure increase. The limit ratio between displacement and inter-storey height is represented with a dotted/dashed red line.

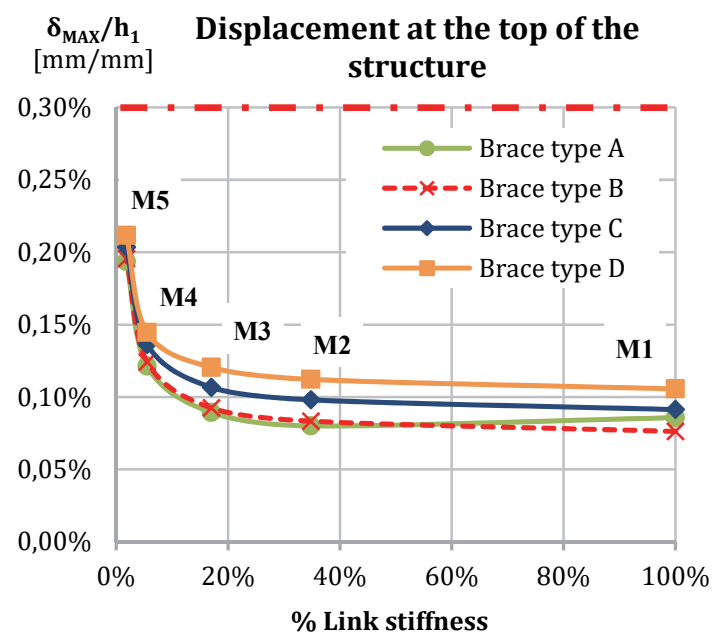

Figure 38: Trend of the absolute displacement at the top of the structure on the relative stiffness of the connecting elements.

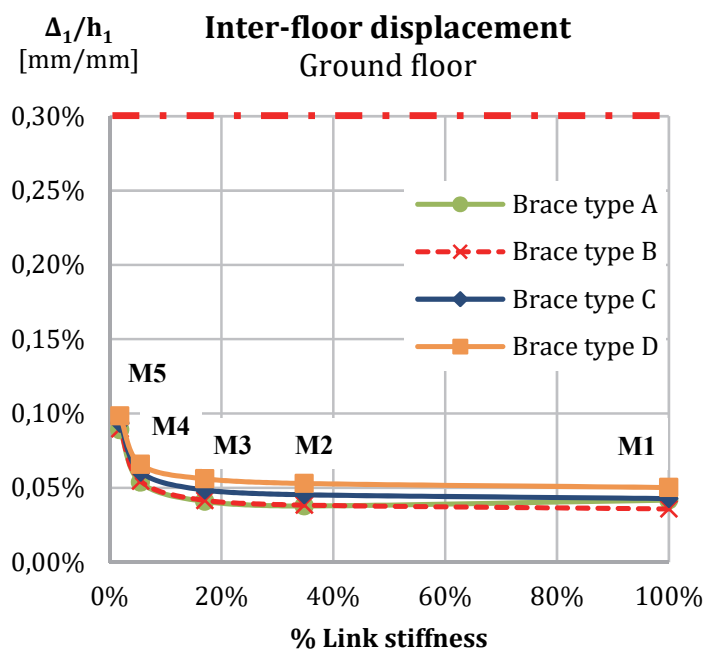

Figure 39: Trend of the inter-floor displacement on the relative stiffness of the connecting elements - Ground floor.

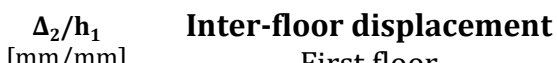
First floor

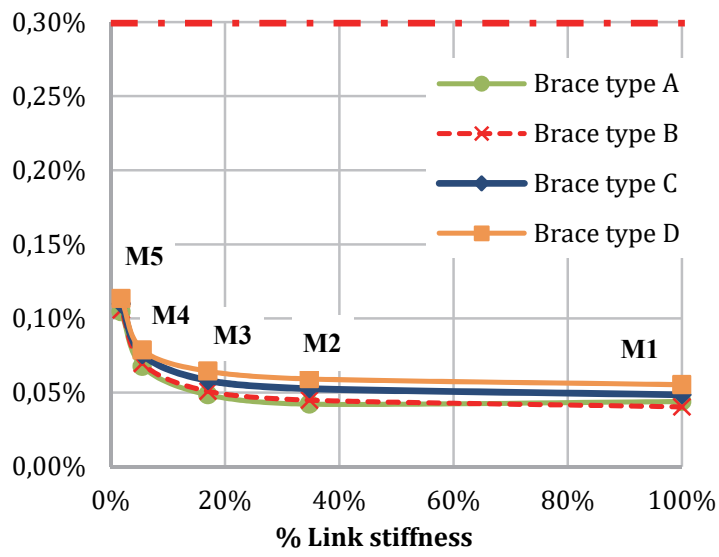

Figure 40: Trend of the inter-floor displacement on the relative stiffness of the connecting elements - First floor.

Finally, the behaviour of the link at collapse is analysed (Fig. 41).

The yielding is achieved only for M5. The other link configurations (M4-M0) are not dissipative.

The stiffness of the bracing system does not significantly affect the response. Instead, the effectiveness of the intervention is more evident if the decrement of the link stiffness is considered. This is related to a "shape effect" of the resisting structure (trusses vs bend structure).

The limit for the formation of the plastic hinge is represented with a dashed red line.

\section{Change in the type of link end constraint}

The analysis shows a significant correlation between the stiffness of the link and its bending behaviour. For this reason, the degree of constraint at one end of the links is changed. 
Initially the links are modelled as a doubly fixed beam. The degree of constraint of the extremity of the link varies from the fixed constraint to the real hinge. In particular, the ratio between the stress moments present at the end of the link $\left(\mathrm{M}_{\mathrm{A}} /\right.$ $\mathrm{M}_{\mathrm{B}}$ ) has been gradually modified as shown in Tab. 8 .

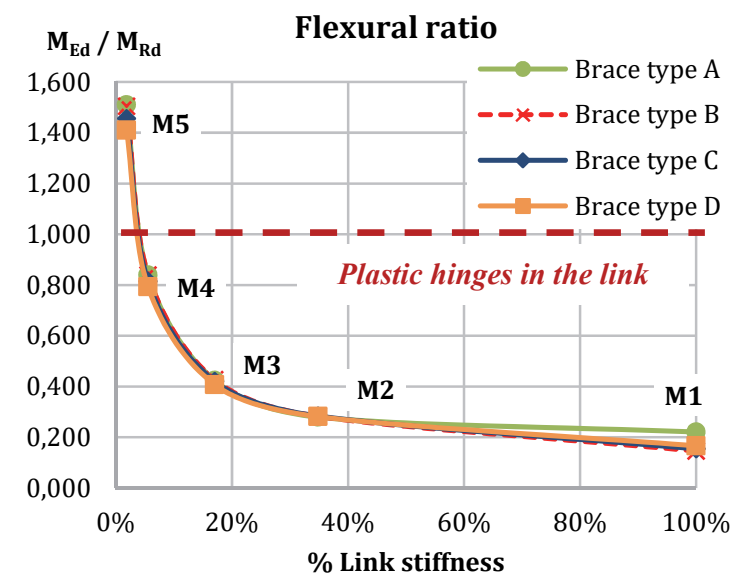

Figure 41: Trend of the ratio between flexural demand and capacity on the relative link stiffness.

\begin{tabular}{cc}
\hline \multicolumn{2}{c}{ Extremity Moment Ratio } \\
Case & $\mathrm{M}_{\mathrm{A}} / \mathrm{M}_{\mathrm{B}}$ \\
R1 & 1.00 \\
R2 & 0.75 \\
R3 & 0.50 \\
R4 & 0.25 \\
R5 & 0.00 \\
\hline \multicolumn{2}{c}{ Table 8: Cases analysed }
\end{tabular}

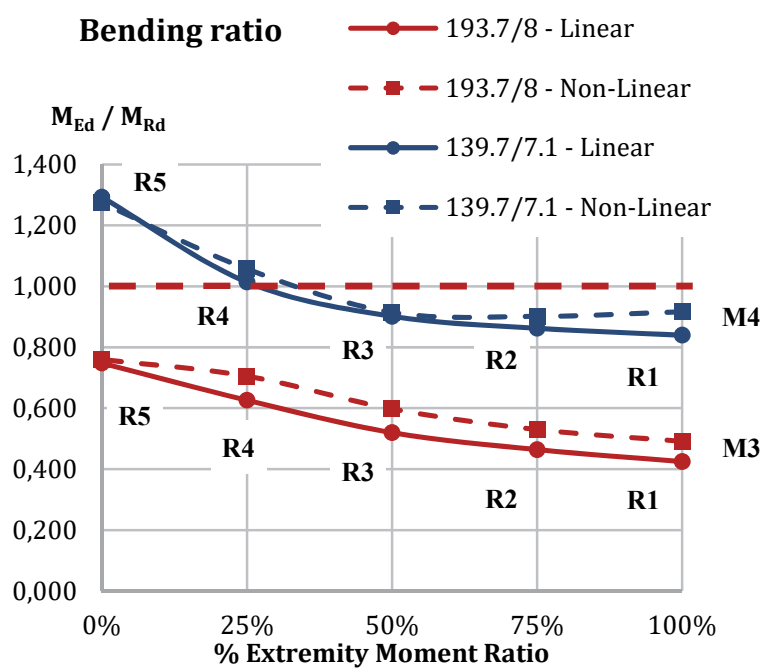

Figure 42: Trend of the ratio between flexural demand and capacity on the extremity moment ratio. The limit for the formation of the plastic hinge is represented with a dashed red line.

This type of analysis is carried out for the brace type A with two kinds of links: (1) tube D 193.7 s 8 (Model M3) and (2) tube D 139.7 s 7.1 (Model M4). 
Reducing the degree of the constraint of one end of the link produces a stress concentration on the opposite side. The results obtained for the link capacity assessment are reported in Fig. 42.

The link plasticization is obtained in cases R4 and R5 for link (M4). This type of link would not have reached the plasticization in the doubly clamped case, which instead allows a greater dissipation of energy.

In this way, the connecting element becomes a non-negligible reserve of ductility that can safeguard the structure during the earthquake.

\section{CONCLUSIONS}

I $\mathrm{n}$ this work a structural optimization of a bracing system through dissipative links is proposed.

Usually the introduction of dissipative links requires expensive and advanced technological systems. In this paper the dissipative links are simulated with commercial profiles. The system analysed here is characterized by a low cost and it is quite different from the common typology proposed for this kind of application.

The procedure is carried out through a benchmark model. This considers the progressive reduction of the cross-section for the links (model from M0 to M5) and for the diagonals (from BTA to BTD).

Some control parameters are assessed. In particular maximum displacement is checked, and the structural behaviour of the existing building bearing elements is checked considering the Italian standard [24]. This procedure shows that it is possible to obtain a substantial economic saving in the design of the tradition intervention. The study of the benchmark model shows that it is possible to obtain an economic saving of about $42 \%$ of the total material cost.

In addition, the comparison between linear and non-linear analysis allows the authors to make a comparison between these two kinds of analysis in the optimization, providing a useful tool for structural designers.

The introduction of dissipative links also improves the structural response of the buildings even in case of geometric and mechanical irregularity. In this sense dissipative links can be used as a strategic design parameter.

This strategy of intervention consents to protect the system taking into account internal actions and maximum displacements. The evaluation of the latter is not specifically required for existing buildings but is a benchmark for the effectiveness of the intervention.

The localization of the dissipative elements at the interface between the building and the bracing system produces a low cost "mechanical fuse" that is easy to replace after a destructive earthquake. These elements can be designed optimizing the cross-section and length of the links in order to reduce the costs.

\section{ACKNOWLEDGEMENTS}

7 he authors would like to extend their thanks to the technical departments of the cities of Empoli (FI) and Calcinaia (PI) for their collaboration and the technical data provided.

1 This work also contains the results of some master's theses, in particular the work of Martina Ferrini, Martina Pellegrino, Grazia Di Mento and Claudio Milani.

\section{REFERENCES}

[1] Bonannini, E., Cinotti, M., Puppio, M.L., Sassu, M. (2017). Seismic response of a stock of social housings in Italy with R . C . and masonry materials . vol. 102, Advances in Engineering Research (AER)102, 285 Second International Conference on Mechanics, Materials and Structural Engineering (ICMMSE 2017), pp. 285-91.

[2] Sassu, M., Mistretta, F., Puppio, M.L., Stochino, F. (2017). Esempi di collassi fragili negli appoggi di pannelli prefabbricati in c.a. IF CRASC '17 - IV Convegno di ingegneria forense VII Convegno su crolli, affidabilità strutturale, consolidamento politecnico di.

[3] Stochino, F., Fadda, M.L., Mistretta, F. (2018). Low cost condition assessment method for existing RC bridges, Eng. Fail. Anal., 86(December), pp. 56-71, DOI: 10.1016/j.engfailanal.2017.12.021.

[4] Alecci, V., De Stefano, M. (2018). Building irregularity issues and architectural design in seismic areas, Frat. Ed Integrità Strutt., 13(47), pp. 161-8, DOI: 10.3221/IGF-ESIS.47.13.

[5] Puppio, M.L., Pellegrino, M., Giresini, L., Sassu, M. (2017). Effect of material variability and mechanical eccentricity on the seismic vulnerability assessment of reinforced concrete buildings, Buildings, 7(4), pp. 66, 
DOI: $10.3390 /$ buildings7030066.

[6] Puppio, M.L., Giresini, L., Doveri, F., Sassu, M. (2019). Structural irregularity: The analysis of two reinforced concrete (r.c.) buildings, 7, DOI: 10.5267/j.esm.2018.12.002.

[7] Sassu, M., Puppio, M.L., Mannari, E. (2017). Seismic Reinforcement of a R.C. School Structure with Strength Irregularities throughout External Bracing Walls, Buildings, 7(3), pp. 58, DOI: 10.3390/buildings7030058.

[8] Sassu, M., Stochino, F., Mistretta, F. (2017). Assessment Method for Combined Structural and Energy Retrofitting in Masonry Buildings, Buildings, 7(3), pp. 71, DOI: 10.3390/buildings7030071.

[9] Stochino, F., Mistretta, F., Meloni, P., Carcangiu, G. (2017). Integrated approach for post-fire reinforced concrete structures assessment, Period. Polytech. Civ. Eng., 61(4), pp. 677-699, DOI: 10.3311/PPci.9830.

[10] Giresini, L. (2016). Energy-based method for identifying vulnerable macro-elements in historic masonry churches, Bull. Earthq. Eng., 14(3), pp. 919-42, DOI: 10.1007/s10518-015-9854-7.

[11] Giresini, L., Casapulla, C., Denysiuk, R., Matos, J., Sassu, M. (2018). Fragility curves for free and restrained rocking masonry façades in one-sided motion, Eng. Struct., 164, pp. 195-213, DOI: 10.1016/j.engstruct.2018.03.003.

[12] Casapulla, C., Giresini, L., Sassu, M., Lourenço, P.B. (2017). Rocking and kinematic approaches of masonry walls: state of the art and recent developments, Buildings, , DOI: 10.3390/buildings7030069.

[13] Andreini, M., De Falco, A., Giresini, L., Sassu, M. (2013). Structural analysis and consolidation strategy of the historic Mediceo Aqueduct in Pisa (Italy)., Appl. Mech. Mater., 351-352, pp. $1354-7$.

[14] Giresini, L. (2017).Design strategy for the rocking stability of horizontally restrained masonry walls. In: M. Papadrakakis, M.F., (Ed.), COMPDYN 2017 6th ECCOMAS Thematic Conference on Computational Methods in Structural Dynamics and Earthquake Engineering, Rhodes Island, Greece.

[15] Giresini, L., Sassu, M., Butenweg, C., Alecci, V., De Stefano, M. (2017). Vault macro-element with equivalent trusses in global seismic analyses, Earthq. Struct., 12(4), pp. 409-423, DOI: 10.12989/eas.2017.12.4.409.

[16] Giresini, L., Gioeli, A., Sassu, M. (2013). Seismic Reinforcement of a r.c. Building with External Steel Frameworks: The Case of the Primary School XXV April of Arcola (Italy), Adv. Mater. Res., 834-836, pp. 697-700, DOI: 10.4028.

[17] De Falco, A., Froli, M., Giresini, L., Puppio, M.L., Sassu, M. (2014). A Proposal for the Consolidation of a R.C. Social Housing by Means of External Hybrid Steel-Glass Frameworks, Appl. Mech. Mater., 638-640, pp. 3-8, DOI: 10.4028/www.scientific.net/AMM.638-640.3.

[18] V. Marquez A., E., Lobo-Q, W., C. Vielma, J. (2015). Comparative Analysis of the Energy Dissipation of Steel Buildings with Concentric and Eccentric Braces, Open Civ. Eng. J., 9(May), pp. 295-307, DOI: 10.2174/1874149501509010295.

[19] Milani, C. (2015).Consolidamento sismico dell'edificio scuola media "M. L. King" di Calcinaia (PI). University of Pisa. Thesis Supervisors: Prof. Eng. Sassu, M.; Eng. Puppio, M. L...

[20] Di Mento, G. (2016).Ottimizzazione di controventi dissipativi per la scuola media “ M . L . King ” di Calcinaia (PI). University of Pisa. Thesis Supervisors: Prof. Eng. Sassu, M.; Eng. Puppio, M. L...

[21] Li, J.J. (2010).Earthquake Engineering Simulation with Flexible Cladding System. University of Massachusetts Amherst. Thesis Supervisors: Prof. Civjan, A. S.; Brena, F. S..

[22] Trombetti, T., Gasparini, G., Silvestri, S., Bacci, L. (2011).Utilizzo di link dissipativi isteretici per la mitigazione degli effetti del sisma: valutazione del comportamento strutturale del corpo D dell'ospedale maggiore di Bologna. XXIII Congresso C.T.A., Giornate italiane della costruzione in acciaio.

[23] Ferrini, M. (2018).Vulnerabilità e consolidamento sismico del plesso scolastico “G. Carducci” di Empoli (FI). University of Pisa. Thesis Supervisors: Prof. Eng. Sassu, M.; Eng. Puppio, M. L.; Eng. Giresini, L..

[24] D.M. 17/01/2018. (2018). Aggiornamento delle "Norme Tecniche per le Costruzioni" (in italian).

[25] Gelfi, P. Gelfi, P.(2017). Free Software. Available at: http://gelfi.unibs.it.

[26] FEMA 356. (2000). Pre-standard and Commentary for the Seismic Rehabilitation of Buildings - Applied Technology Council (ATC). 


\section{APPENDIX}

A.1 - Parametric analysis of a connection system with dissipative links, results.

\begin{tabular}{ccccc}
\hline Case & \multicolumn{2}{c}{ Linear Dynamic } & \multicolumn{2}{c}{ Non-linear Dynamic } \\
& $\mathrm{V}_{\mathrm{eb}, \mathrm{x} \%}$ & $\mathrm{~V}_{\mathrm{eb}, \mathrm{y} \%}$ & $\mathrm{~V}_{\mathrm{eb}, \mathrm{x} \%} \%$ & $\mathrm{~V}_{\mathrm{eb}, \mathrm{y} \%}$ \\
M0 & $15 \%$ & $14 \%$ & $16 \%$ & $14 \%$ \\
M1 & $17 \%$ & $16 \%$ & $17 \%$ & $17 \%$ \\
M2 & $19 \%$ & $18 \%$ & $20 \%$ & $19 \%$ \\
M3 & $22 \%$ & $20 \%$ & $23 \%$ & $22 \%$ \\
M4 & $30 \%$ & $27 \%$ & $32 \%$ & $28 \%$ \\
M5 & $46 \%$ & $40 \%$ & $45 \%$ & $43 \%$ \\
\hline
\end{tabular}

Table A.1. 1: Percentage of share at the base of the existing structure

\begin{tabular}{cccc}
\hline Case & \multicolumn{3}{c}{ Linear Dynamic } \\
& $\boldsymbol{\Delta}_{\mathbf{1}}[\mathrm{mm}]$ & $\boldsymbol{\Delta}_{\mathbf{2}}[\mathrm{mm}]$ & $\boldsymbol{\delta}_{\text {MAx }}[\mathrm{mm}]$ \\
M0 & 1.085 & 1.080 & 2.132 \\
M1 & 1.379 & 1.450 & 2.829 \\
M2 & 1.249 & 1.392 & 2.641 \\
M3 & 1.350 & 1.597 & 2.947 \\
M4 & 1.772 & 2.231 & 4.003 \\
M5 & 2.939 & 3.447 & 6.386 \\
\hline
\end{tabular}

Table A.1. 2: Displacements - Linear Analysis

\begin{tabular}{cccc}
\hline Case & \multicolumn{3}{c}{ Non-Linear Dynamic } \\
& $\boldsymbol{\Delta}_{\mathbf{1}}[\mathrm{mm}]$ & $\boldsymbol{\Delta}_{\mathbf{2}}[\mathrm{mm}]$ & $\boldsymbol{\delta}_{\text {MAx }}[\mathrm{mm}]$ \\
M0 & 1.085 & 1.080 & 2.132 \\
M1 & 1.379 & 1.450 & 2.829 \\
M2 & 1.249 & 1.392 & 2.641 \\
M3 & 1.350 & 1.597 & 2.947 \\
M4 & 1.772 & 2.231 & 4.003 \\
M5 & 2.939 & 3.447 & 6.386 \\
\hline
\end{tabular}

Table A.1. 3: Displacements - Non-Linear Analysis 


\begin{tabular}{cccc}
\hline Case & \multicolumn{3}{c}{ Linear Dynamic } \\
M0 & M (1) & V (2) & $\Theta(3)$ \\
M1 & Rigid & Rigid & Rigid \\
M2 & 0.143 & 0.062 & 0.022 \\
M3 & 0.280 & 0.098 & 0.044 \\
M4 & 0.425 & 0.120 & 0.077 \\
M5 & 0.840 & 0.173 & 0.129 \\
\hline
\end{tabular}

Table A.1. 4: Link Collapse Mode

\begin{tabular}{cccc}
\hline Case & \multicolumn{3}{c}{ Non-Linear Dynamic } \\
M0 & R (1) & $\theta(3)$ \\
M1 & Rigid & 0.103 & Rigid \\
M2 & 0.221 & 0.130 & 0.021 \\
M3 & 0.358 & 0.142 & 0.040 \\
M4 & 0.491 & 0.190 & 0.070 \\
M5 & 0.917 & 0.237 & 0.207 \\
\hline
\end{tabular}

Table A.1. 5: Link Collapse Mode

\section{A.2 - Bracing System Optimization}

\begin{tabular}{ccccc}
\hline Case & \multicolumn{2}{c}{ Brace type A } & \multicolumn{2}{c}{ Brace type B } \\
& $\mathrm{V}_{\mathrm{eb}, \mathrm{x} \%}$ & $\mathrm{~V}_{\mathrm{eb}, \mathrm{y} \%}$ & $\mathrm{~V}_{\mathrm{eb}, \mathrm{x} \%}$ & $\mathrm{~V}_{\mathrm{eb}, \mathrm{y} \%}$ \\
M0 & $15 \%$ & $14 \%$ & $15 \%$ & $16 \%$ \\
M1 & $17 \%$ & $16 \%$ & $17 \%$ & $18 \%$ \\
M2 & $19 \%$ & $18 \%$ & $19 \%$ & $19 \%$ \\
M3 & $22 \%$ & $20 \%$ & $22 \%$ & $21 \%$ \\
M4 & $30 \%$ & $27 \%$ & $31 \%$ & $28 \%$ \\
M5 & $46 \%$ & $40 \%$ & $46 \%$ & $41 \%$ \\
\hline
\end{tabular}

Table A.2. 1: Share at the base - existing structure 


\begin{tabular}{ccccc}
\hline & \multicolumn{2}{c}{ Brace type C } & \multicolumn{2}{c}{ Brace type $\mathbf{D}$} \\
\hline Case & $\mathrm{V}_{\mathrm{eb}, \mathrm{x} \%}$ & $\mathrm{~V}_{\mathrm{eb}, \mathrm{y} \%} \%$ & $\mathrm{~V}_{\mathrm{eb}, \mathrm{x} \%}$ \\
& $19 \%$ & $20 \%$ & $22 \%$ & $23 \%$ \\
M0 & $21 \%$ & $21 \%$ & $24 \%$ & $24 \%$ \\
M1 & $23 \%$ & $22 \%$ & $26 \%$ & $25 \%$ \\
M2 & $25 \%$ & $24 \%$ & $35 \%$ & $27 \%$ \\
M3 & $33 \%$ & $31 \%$ & $50 \%$ & $32 \%$ \\
M4 & $48 \%$ & $43 \%$ & $45 \%$ \\
M5 & &
\end{tabular}

Table A.2. 2: Share at the base - existing structure

\begin{tabular}{cccc}
\hline Case & \multicolumn{3}{c}{ Brace type A } \\
& $\Delta_{1}[\mathrm{~mm}]$ & $\Delta_{2}[\mathrm{~mm}]$ & $\delta_{\mathrm{MAx}}[\mathrm{mm}]$ \\
M0 & 1.085 & 1.080 & 2.132 \\
M1 & 1.379 & 1.450 & 2.829 \\
M2 & 1.249 & 1.392 & 2.641 \\
M3 & 1.350 & 1.597 & 2.947 \\
M4 & 1.772 & 2.231 & 4.003 \\
M5 & 2.939 & 3.447 & 6.386 \\
\hline
\end{tabular}

Table A.2. 3: Displacements - Linear Analysis

\begin{tabular}{cccc}
\hline Case & \multicolumn{3}{c}{ Brace type B } \\
& $\Delta_{1}[\mathrm{~mm}]$ & $\Delta_{2}[\mathrm{~mm}]$ & $\delta_{\text {MAx }}[\mathrm{mm}]$ \\
M0 & 1.105 & 1.182 & 2.253 \\
M1 & 1.183 & 1.331 & 2.514 \\
M2 & 1.268 & 1.481 & 2.749 \\
M3 & 1.373 & 1.678 & 3.051 \\
M4 & 1.799 & 2.295 & 4.094 \\
M5 & 2.960 & 3.489 & 6.449 \\
\hline
\end{tabular}

Table A.2. 4: Displacements - Linear Analysis

\begin{tabular}{cccc}
\hline Case & \multicolumn{3}{c}{ Brace type C } \\
M0 & $\Delta_{1}[\mathrm{~mm}]$ & $\Delta_{2}[\mathrm{~mm}]$ & $\delta_{\text {MAX }}[\mathrm{mm}]$ \\
M1 & 1.321 & 1.464 & 2.775 \\
M2 & 1.413 & 1.600 & 3.013 \\
M3 & 1.498 & 1.737 & 3.235 \\
M4 & 1.602 & 1.918 & 3.520 \\
M5 & 2.001 & 2.496 & 4.497 \\
\hline
\end{tabular}

Table A.2. 5: Displacements - Linear Analysis 


\begin{tabular}{cccc}
\hline Case & \multicolumn{3}{c}{ Brace type D } \\
& $\Delta_{1}[\mathrm{~mm}]$ & $\Delta_{2}[\mathrm{~mm}]$ & $\delta_{\mathrm{MAx}}[\mathrm{mm}]$ \\
M0 & 1.570 & 1.702 & 3.259 \\
M1 & 1.659 & 1.825 & 3.484 \\
M2 & 1.748 & 1.953 & 3.701 \\
M3 & 1.850 & 2.124 & 3.974 \\
M4 & 2.171 & 2.597 & 4.768 \\
M5 & 3.243 & 3.740 & 6.983 \\
\hline
\end{tabular}

Table A.2. 6: Displacements - Linear Analysis

\begin{tabular}{cccc}
\hline Case & \multicolumn{3}{c}{ Brace type A } \\
M0 & Rigid $(1)$ & V (2) & R (3) \\
M1 & 0.143 & Rigid & Rigid \\
M2 & 0.280 & 0.062 & 0.022 \\
M3 & 0.425 & 0.098 & 0.044 \\
M4 & 0.840 & 0.120 & 0.077 \\
M5 & 1.510 & 0.173 & 0.129 \\
& Table A.2. 7: Link Collapse Mode & 0.482 \\
\hline Case & & 0.225 & \\
M0 & Brace type B & (1) $(3)$ \\
M1 & Rigid & V (2) & Rigid \\
M2 & 0.146 & Rigid & 0.022 \\
M3 & 0.283 & 0.063 & 0.044 \\
M4 & 0.427 & 0.098 & 0.077 \\
M5 & 0.840 & 0.121 & 0.128 \\
& 1.504 & 0.173 & 0.480 \\
\hline
\end{tabular}

Table A.2. 8: Link Collapse Mode

\begin{tabular}{cccc}
\hline Case & \multicolumn{3}{c}{ Brace type C } \\
& M (1) & V (2) & $\boldsymbol{\theta}(3)$ \\
M0 & Rigid & Rigid & Rigid \\
M1 & 0.155 & 0.060 & 0.023 \\
M2 & 0.284 & 0.093 & 0.044 \\
M3 & 0.420 & 0.114 & 0.075 \\
M4 & 0.815 & 0.166 & 0.181 \\
M5 & $\mathbf{1 . 4 5 6}$ & 0.216 & 0.464 \\
\hline
\end{tabular}

Table A.2. 9: Link Collapse Mode 


\begin{tabular}{cccc}
\hline Case & \multicolumn{3}{c}{ Brace type D } \\
& M (1) & V (2) & $\boldsymbol{\theta}(3)$ \\
M0 & Rigid & Rigid & Rigid \\
M1 & 0.167 & 0.058 & 0.026 \\
M2 & 0.282 & 0.088 & 0.046 \\
M3 & 0.408 & 0.108 & 0.077 \\
M4 & 0.793 & 0.160 & 0.173 \\
M5 & $\mathbf{1 . 4 1 0}$ & 0.208 & 0.451 \\
\hline
\end{tabular}

A.3 - Change in the type of link end constraint

\begin{tabular}{cccc}
\hline Case & \multicolumn{3}{c}{ D 193.7 s 8 - Linear Dynamic } \\
R1 & M (1) & V (2) & $\theta(3)$ \\
R2 & 0.425 & 0.120 & 0.077 \\
R3 & 0.464 & 0.119 & 0.097 \\
R4 & 0.520 & 0.118 & 0.124 \\
R5 & 0.626 & 0.114 & 0.179 \\
\hline
\end{tabular}

Table A.3. 1. Link Collapse Mode

\begin{tabular}{cccc}
\hline Case & \multicolumn{3}{c}{ D 193.7 s 8- Non-Linear Dynamic } \\
R1 & M (1) & V (2) & $\theta(3)$ \\
R2 & 0.491 & 0.142 & 0.070 \\
R3 & 0.530 & 0.141 & 0.090 \\
R4 & 0.598 & 0.139 & 0.121 \\
R5 & 0.705 & 0.128 & 0.188 \\
& 0.760 & 0.112 & 0.232 \\
\hline Case & Table A.3. 2: Link Collapse Mode & \\
R1 & D 139.7 s 7.1 - Linear Dynamic \\
R2 & M (1) & V (2) & 0.200 \\
R3 & 0.840 & 0.173 & 0.219 \\
R4 & 0.862 & 0.171 & 0.252 \\
R5 & 0.902 & 0.168 & 0.347 \\
\hline
\end{tabular}

Table A.3. 3: Link Collapse Mode 
M. L. Puppio et alii, Frattura ed Integrità Strutturale, 48 (2019) 706-739; DOI: 10.3221/IGF-ESIS.48.66

\begin{tabular}{cccc}
\hline Case & \multicolumn{3}{c}{ D 139.7 s 7.1 - Non-Linear Dynamic } \\
R1 & M (1) & V (2) & $\Theta(3)$ \\
R2 & 0.917 & 0.190 & 0.207 \\
R3 & 0.901 & 0.183 & 0.217 \\
R4 & 0.915 & 0.173 & 0.242 \\
R5 & 1.057 & 0.168 & 0.319 \\
\hline
\end{tabular}

Table A.3. 4: Link Collapse Mode 